\title{
Analysis of a Decentralized Supply Chain Under Partial Cooperation
}

\author{
Refik Güllü \\ Industrial Engineering Department, Bogazici University, Bebek 34342 Istanbul, Turkey, refik.gullu@boun.edu.tr
}

Geert-Jan van Houtum

Department of Technology Management, Technische Universiteit Eindhoven, P.O. Box 513, 5600 MB Eindhoven, The Netherlands, g.j.v.houtum@tm.tue.nl

F. Zeynep Sargut

Industrial and Systems Engineering Department, University of Florida, 303 Weil Hall, Gainesville, Florida 32611-6595, zeynep@ufl.edu

Nesim Erkip

Department of Industrial Engineering, Bilkent University, 06800 Ankara, Turkey, nesim@bilkent.edu.tr

\begin{abstract}
In this article, we analyze a decentralized supply chain consisting of a supplier and two independent retailers. In each order cycle, retailers place their orders at the supplier to minimize inventory-related expected costs at the end of their respective response times. There are two types of lead times involved. At the end of the supplier lead time, retailers are given an opportunity to readjust their initial orders (without changing the total order size), so that both retailers can improve their expected costs at the end of respective retailer lead times (the time it takes for items to be shipped from the supplier to the retailers). Because of the possibility of cooperation at the end of supplier lead time, each retailer will consider the other's order-up-to level in making the ordering decision. Under mild conditions, we prove the existence of a unique Nash equilibrium for the retailer orderup-to levels, and show that they can be obtained by solving a set of newsboy-like equations. We also present computational analysis that provides valuable managerial insight for design and operation of decentralized systems under the possibility of partial cooperation.
\end{abstract}

Key words: multiperiod decentralized inventory; partial cooperation; Nash equilibrium; transshipment History: Received: March 17, 2003; accepted: May 5, 2005. This paper was with the authors 11 months for

4 revisions.

\section{Introduction and Motivation}

In this article, we investigate a decentralized supply chain of two independent retailers (or manufacturers) and a supplier. In the system that we analyze, retailers order a common product (or raw material) from the supplier to fulfill their own random customer demand. We consider a periodic review system where each retailer places an order at regular intervals to raise its inventory position to a predetermined level. The supplier has ample capacity to satisfy the orders placed by the retailers, but there is a fixed lead time (supplier lead time) associated with order preparation (because of supplier's manufacturing or ordering lead time, packaging, and loading times at the supplier's plant, and possibly transportation time to the warehouse). At the end of the supplier lead time, orders are shipped to retailers. We also assume that there is a fixed shipment lead time associated with each retailer (retailer lead time). When the order is received by a retailer, it is used to satisfy the customer demand and accordingly inventory-related holding and backorder costs are incurred.

When orders are ready to be shipped (at the end of the supplier lead time) there is an ideal inventory position for retailers that they would like to attain, which minimizes their inventory-related expected costs at the end of their respective response time (retailer lead time plus one period). However, as the demand observed during the supplier lead time is random, their realized inventory positions 
will be either below or above that particular level (if demands are assumed to be continuous, being at the ideal level has zero probability). Therefore, a possible transfer of retailer orders at the supplier's plant (or at the cross-docking warehouse), before they are shipped to retailers, may improve the inventoryrelated costs of the retailers. However, as the supply chain is decentralized, retailers will allow such a transaction only if the transfer yields an improvement for both of them. In Figure 1, we provide an illustration of the system. Our setting fits best for systems where the supplier-retailer chain cannot enjoy the full benefits of centralized decision making, but a room for cooperation still exists, if it improves the performance of both retailers. We detail the extend of cooperation between retailers by referring to the following examples:

(1) Consider two manufacturing plants in Europe, operating under the same corporation but serving different markets. Managers of each plant are evaluated with respect to their own performance. They order computer chips from an Asian supplier and they agree on readjusting their original orders at the end of the supplier lead time provided that it does not deteriorate their own performance. Because the readjustment will not affect the total quantity ordered from the supplier, no costs are associated with such a transaction. A typical example would be to have two manufacturers, one in Rotterdam and the other in Switzerland that are collaborating. The shipment time from Asia is approximately four to five weeks. Depending on the item in question, the order interval may very well be once in every month or less frequent. Hence it may be the case that the lead time from the supplier is less than the reorder interval of the manufacturers.

Figure 1 Illustration of Supply Chain

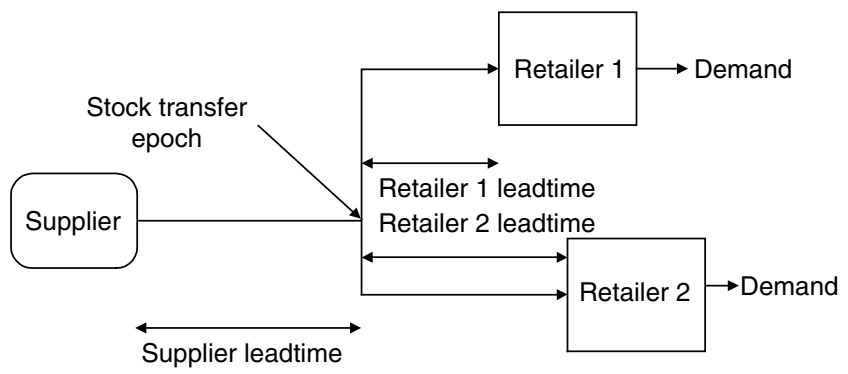

(2) Consider two retail stores for an apparel chain, supplied through a common regional cross-docking warehouse. Orders can be readjusted at the warehouse just before the trucks are loaded. Again, both stores would agree to such a transaction as long as it improves their performances.

As depicted in Figure 1, an order cycle is divided into two subcycles. At the beginning of the order cycle, each retailer places an order at the supplier. At the end of the first subcycle (at the end of the supplier lead time), retailers reassess their stock position, and decide whether a transfer of stock is to occur. Then, they inform the supplier (or the cross-docking warehouse) of their decision. Because no physical transshipment takes place (the transaction occurs either at the suppliers plant or at the cross-docking warehouse), we assume that the cost of transfer is negligible. Each retailer starts the second subcycle with its new inventory position, and at the end of the order cycle, associated costs are incurred.

The main objective of this article is to characterize the optimal order-up-to levels that the retailers base their ordering amounts from the supplier. Because there is a possibility of stock transfer at the supplier, the order-up-to level of one retailer would have an affect on the choice of order-up-to level of the other retailer (consider the extreme case, where one retailer places an order of size infinity, and therefore it is always willing to transfer any required amount to the other retailer). Moreover, if retailers share relevant information (such as costs, demand distributions, inventory levels), then each retailer can compute its order-up-to level with the knowledge of the other retailer's possible inventory decision. This leads to a Nash equilibrium setting. Note that this model is decentralized as each retailer tries to minimize its own inventory-related costs. We would like to obtain the equilibrium solution of the system described above, and measure its potential benefits.

To be able to assess the benefits of the model that we pose, we specify the following three models (one of them being the one that we propose), each with a different degree of interaction between retailers:

(1) Decentralized model with stock transfer. This is the proposed model. Each retailer determines its orderup-to level independently, but with the knowledge 
of other retailer's relevant information (such as costs, demand distributions, inventory levels). Moreover, retailers allow stock transfer at the supplier's site as long as a transfer improves expected costs of both retailers.

(2) Decentralized model without stock transfer. Retailers determine their order-up-to levels independently, and they do not exercise the stock transfer. In this model, there is no information sharing between retailers.

(3) Centralized model. Instead of determining individual order-up-to levels for the retailers, a systemwide order-up-to level that minimizes expected total costs is obtained. Then, at the end of the supplier lead time, each retailer is allocated a stock amount that will minimize the systemwide expected cost. With the help of the models posed, we also would like to answer several questions pertaining to the behavior of the system. The answers to the following questions are expected to yield important managerial insight on operation of such systems:

(1) What is the degree of improvement (in terms of costs and safety stocks) gained by stock transfer and information availability between retailers?

(2) How far is the performance of the proposed model from the centralized model?

(3) Which form of collaboration brings the most benefits (transfer of stock or using the knowledge of other retailer's order-up-to level in determining the order quantity)?

In this article, we make four major contributions: (1) we present and analyze a model of a decentralized supply chain where a retailer determines its order-up-to level by taking into account the possibility of transfer of stock and with the knowledge of other retailer's relevant information, (2) under this setting, we prove the existence of a unique Nash equilibrium of retailer order-up-to levels, (3) we introduce a key random variable, the net change in the retailer stock position after readjustment of retailer orders, and provide its distribution function, which facilitates an explicit characterization of optimal orderup-to level through a newsboy-like equation, and (4) we present our computational analysis that provides valuable managerial insight for design and operation of decentralized systems under the possibility of stock transfer.
The rest of this paper is organized as follows. In §2, we review the related literature. In $\S 3$, we present the mathematical model and derive the expected cycle costs for the retailers. Our analysis relies on the characterization of a random variable denoting the net change in a retailer's stock position after transfer of stock occurs. In $\S 4$, we derive the distribution function of that random variable, and discuss its various properties. We prove the existence of a unique Nash equilibrium in \$5. Computational findings and discussion of results are presented in $\S 6$. We present our concluding remarks and discuss extensions in $§ 7$.

\section{Related Literature}

A stream of research related to ours is the two-echelon inventory models with transshipment. Such systems are widely studied in the literature when the decision making is centralized. Krishnan and Rao (1965) and Gross (1963) are early examples of models with transshipment. Das (1975) extends the single-period model of Gross (1963) to allow transshipments in a certain epoch within the period. Das (1975) argues optimality of base stock conserving (BSC) transfer rules. Under a BSC transshipment, the excess stock of one location (over its base stock level) is transshipped to another location (if it has a shortage with respect to its base stock level). Tagaras (1989) considers a similar model but restricts transshipment epoch to the end of a period. Robinson (1990) and Tagaras (1999) extend earlier studies to multilocation environments. Robinson (1990) shows the optimality of a myopic base stock policy for the case of identical retailers. Our basic difference from these papers is that the locations in our model make their decisions independently, rather than seeking to achieve a joint objective function.

A more general body of related literature is on risk pooling, though the ideas here are more specific. Nevertheless, we use the risk-pooling notions of Eppen and Schrage (1981) in our computational analysis for benchmarking the benefits introduced by the proposed model. A more recent paper that explicitly considers centralization with risk pooling is Cherikh (2000). In Cherikh (2000), risk pooling is achieved by a limited transshipment policy, in a way resembling our proposal, under a multifacility newsvendor setting. 
Another related direction of research is the coordination issues of decentralized supply chains. Most of these papers consider incentive schemes between the supplier and the retailer(s) to achieve the centralized solution (see, for example, Cachon and Zipkin 1999, Chen 1999, Lee and Whang 1999, Cachon 2001).

Game-theoretic consumer choice models, as they impose an interaction among retailers, are related to stock transfer models that we investigate. Parlar (1988) considers two substitutable products, where excess demand for an item is directed to other item's stock. Parlar (1988) proves the existence and uniqueness of the Nash solution in a single-period setting. Wang and Parlar (1994) extend Parlar (1988) to a three-product case. Avsar and Gursoy (2002) consider a multiperiod extension of Parlar (1988), and show the existence of a myopic Nash solution (within the class of stationary policies) for the infinite horizon case. In Lippman and McCardle (1997), industry demand for an item is allocated across locations using specific splitting rules. After the allocation of demand, excess demand is reallocated in a way similar to Parlar (1988). They characterize the Nash equilibrium of inventory levels and show that it is unique under certain conditions. Mahajan and van Ryzin (2001) analyze a system where consumers choose dynamically from the available products based on a utility maximization criterion. They show that competition among locations leads to overstocking, which in the limit, becomes so excess that the individual profits of locations approach to zero. We differ from the consumer choice models reviewed above in two important aspects. In the above-mentioned articles, excess demand is transferred across locations, whereas we consider the transfer of stock. Also, the transfer of demand from one location to another occurs after the realization of demand (with respect to a single orderup-to level computed at the beginning of a single period), whereas in our model, we consider the transfer of stock after the occurrence of the supplier lead time demand, but before the realization of retailer lead time demand is observed. Therefore, in our analysis, the stock position (right before the realization of retailer lead time demand) of a retailer is not only affected by the excess demand in the other retailer, but also affected by the occurrence of shortage (with respect to retailer lead time order-up-to level).
In a recent paper by Rudi et al. (2001), consider a two-retailer decentralized model with transshipment of stock. The authors aim to find transshipment prices for which the joint decentralized profit achieves the centralized system profit. Anupindi et al. (2001) employ a general framework with $N$ retailers. Each location makes independent inventory decision (how much to stock), demands are observed, and then locations jointly determine the shipment decision (how to allocate the excess demand). For the inventory decision, Anupindi et al. (2001) develop conditions for the existence of a pure strategy Nash equilibrium. They also show that there exists an allocation mechanism for the decentralized system that achieves the centralized solution. Both the motivation and the analysis of this paper differ from these papers in the following respects. In our work, we model a system differentiated by (possibly long) lead times that are observed both prior and after the transfer of stock occurs. Therefore, as well as the determination of the transfer (or allocation of stock) decision that occurs after the realization of supplier lead time, and the determination of the inventory decision that precedes the supplier lead time, we are also interested in the consequences of these decisions in the posttransfer periods (through the retailer lead time). As mentioned in \$1, a cross-docking distribution system, where the replenishment cycle is decomposed into to warehouse and from warehouse lead times provides a good example. In such a case, not only the inventory decision at the beginning of the cycle but also the revised decision at some epoch within the cycle becomes important. The managers of the retailers are interested in the impact of their inventory and transfer decisions with respect to the order-up-to levels computed relative to the retailer shipment times. In our analysis, we derive and employ the distribution of net change in the stock position of a retailer as a function of both the original order-up-to levels and order-up-to levels relative to retailer shipment times. This distribution enables us to analyze important system dynamics with respect to essential system characteristics.

\section{Description of the Mathematical Model}

In this section, we present our mathematical model. We choose to describe the details using a single order 
cycle to ease the exposition. Notation and basic definitions are laid out in $\$ 3.1$. Note that we use notation and definitions suitable for the stationary problem. In $\S 3.2$, we derive the expected cost function of a retailer. In $\S 3.3$, we introduce the general periodic review model, and state and discuss the conditions under which the single cycle analysis will hold for the stationary problem. These conditions are mild, as will be observed in $\S 3.3$.

\subsection{Preliminaries and Notation}

The system is comprised of a supplier and two retailers. Suppose time is divided into periods of unit length. Let $L \in\{1,2, \ldots\}$ be the length of the supplier lead time, and $l_{i} \in\{0,1,2, \ldots\}$ be the length of the retailer lead time for retailer $i(i=1,2)$. For the cross-docking example of $\S 1, L$ represents the transportation time of shipping goods from the supplier to the cross-docking warehouse, and $l_{i}$ represents the time it takes to ship goods from the warehouse to the retailer. We define $D_{i, t}$ as the demand observed at retailer $i$ in period $t$, and we let $D_{i}(k)$ be the generic continuous random variable denoting total demand occurring at retailer $i(i=1,2)$ over $k$ periods $(k=$ $1,2, \ldots)$. Although we assume that retailer demands are independent through time and across retailers, in $\S 4$, we argue that this restriction can be relaxed. Let $F_{i}^{(k)}(x)$ be the distribution function for $D_{i}(k)$. We assume that $F_{i}^{(1)}(x)$ is continuously differentiable and strictly increasing on the support $(0, \infty)$ with no mass at $x=0$. Our results would hold for distribution functions over a finite support as well. Let $f_{i}^{(k)}(x)$ be the density function of $D_{i}(k)$.

At the beginning of a period (denoted as the first period for notational convenience), retailer $i$ places an order at the supplier to raise its inventory position to level $S_{i}(i=1,2)$. When retailers determine their order-up-to levels, inventory decision of one retailer depends on the other. Therefore, for a given inventory decision $S_{2}$ of retailer 2, the optimal inventory level of retailer 1 is denoted as $S_{1}^{*}\left(S_{2}\right)$. To simplify the notation, we suppress the dependency of $S_{1}^{*}$ (and of $S_{2}^{*}$ ) on the other retailer's decision, and use $S_{i}^{*}$ to denote the optimal value for $S_{i}$ whenever appropriate.

For each retailer, we focus on a replenishment cycle of length $L+l_{i}+1$, as the impact of the inventory decision made at the beginning of the cycle affects inventory-related costs of a retailer at the end of period $L+l_{i}+1$. At the beginning of period $L+1$, each retailer has its own ideal inventory position that it would like to achieve to minimize respective holding and backorder costs to be incurred at the end of period $L+l_{i}+1$. Let $Z_{1}$ and $Z_{2}$ be these ideal levels for retailers 1 and 2, respectively. We denote the holding and backorder costs associated with retailer $i$ as $h_{i}>0$ and $b_{i}>0(i=1,2)$, respectively.

\subsection{Development of the Expected Cost Functions} We first derive the ideal stock position, $Z_{i}$, that retailer $i$ would like to attain at the beginning of period $L+1$. To compute $Z_{i}$, we concentrate on demands occurring in periods $L+1, L+2, \ldots$, $L+l_{i}+1$ : simply, $Z_{i}$ is the base stock level for an inventory system where the response time are the periods $L+1, L+2, \ldots, L+l_{i}+1$. Let $G_{i}(z)$ be the expected single-period cost observed at retailer $i$, given that the inventory position at the beginning of period $L+1$ (after any transfer transaction is realized) is $z$ :

$$
\begin{aligned}
G_{i}(z)= & h_{i} \int_{0}^{z}(z-x) f_{i}^{\left(l_{i}+1\right)}(x) d x \\
& +b_{i} \int_{z}^{\infty}(x-z) f_{i}^{\left(l_{i}+1\right)}(x) d x .
\end{aligned}
$$

Because $G_{i}(z)$ is strictly convex (by assumptions imposed on $\left.F_{i}^{\left(l_{i}+1\right)}(x)\right)$, the optimal inventory position for retailer $i$ after any transfer transaction is uniquely given by

$$
F_{i}^{\left(l_{i}+1\right)}\left(Z_{i}\right)=\frac{b_{i}}{h_{i}+b_{i}} .
$$

For notational convenience, define

$$
\Delta_{i}=S_{i}-Z_{i} .
$$

Let $A_{i}$ and $B_{i}$ be the random variables denoting excess and shortfall inventory for retailer $i$ relative to $Z_{i}$ at the end of period $L$ (before any reallocation decision):

$$
\begin{aligned}
& A_{i}=\left(\Delta_{i}-D_{i}(L)\right)^{+}, \\
& B_{i}=\left(D_{i}(L)-\Delta_{i}\right)^{+},
\end{aligned}
$$

where $(x)^{+}=\max \{0, x\}$. Note that realizations of $A_{i}$ and $B_{i}$ cannot be both positive. We define random variables $\eta_{1}$ and $\eta_{2}$ as follows:

$$
\begin{aligned}
\eta_{1}= & \text { amount that can be transferred from retailer } 2 \\
& \text { to retailer } 1 \\
= & \min \left\{B_{1}, A_{2}\right\}
\end{aligned}
$$


$\eta_{2}=$ amount that can be transferred from retailer 1 to retailer 2

$$
=\min \left\{B_{2}, A_{1}\right\} .
$$

We define $X_{i}$ as the net change in the stock position of retailer $i$ at the end of period $L$ after any transfer transaction is completed:

$$
\begin{aligned}
& X_{1}=D_{1}(L)-\eta_{1}+\eta_{2}, \\
& X_{2}=D_{2}(L)-\eta_{2}+\eta_{1} .
\end{aligned}
$$

We note that $\eta_{1}$ and $\eta_{2}$ cannot be both positive and both $X_{1}$ and $X_{2}$ are functions of $S_{1}$ and $S_{2}$ (actually, of $\Delta_{1}$ and $\Delta_{2}$, but $Z_{1}$ and $Z_{2}$ can be found by Equation (2)). We define $C_{i}\left(S_{1}, S_{2}\right)$ as the expected inventory holding and backorder costs of retailer $i$ at the end of period $L+l_{i}+1$ :

$$
C_{i}\left(S_{1}, S_{2}\right)=E\left[G_{i}\left(S_{i}-X_{i}\right)\right],
$$

where the expectation is taken over $X_{i}$. Because retailer $i$ would like to get as close to its $\left(l_{i}+1\right)$ period optimal inventory position $Z_{i}$ after any transfer occurs, intuitively, for any given $S_{j}(j \neq i), S_{i}$ that minimizes (4) should be bounded below by $Z_{i}$. We formalize this observation for retailer 1 in the following proposition (the argument for retailer 2 is the same).

Proposition 1. Let $S_{1}^{*}\left(S_{2}\right)$ be the minimizer of $C_{1}\left(S_{1}, S_{2}\right)$ over $S_{1}$ for a given value of $S_{2}$. Then, $S_{1}^{*}\left(S_{2}\right) \geq Z_{1}$.

Proof. Proof is provided in the appendix.

By Proposition 1, we may limit our analysis to nonnegative $\Delta_{i}$. Then, $X_{i} \geq 0$ for $i=1,2$. Let $H_{i}(x)$ be the distribution function of $X_{i}(i=1,2)$. Equation (4) can be rewritten as

$$
C_{i}\left(S_{1}, S_{2}\right)=\int_{0}^{\infty} G_{i}\left(S_{i}-x\right) d H_{i}(x),
$$

where $H_{i}(x)$ is a function of both $S_{1}$ and $S_{2}$.

\subsection{Stationary Problem: Infinitely Many Order Cycles}

Although in this paper we consider a single replenishment cycle, our development can be used as an approximation for the stationary multicycle problem. In what follows, we present an analysis of the multicycle problem, and show that the expected cost function developed in $\$ 3.2$ (specifically, Equation (5)) is still valid under an additional assumption. The difficulty in extending the single-cycle analysis to multiple order cycles is because of the possibility of transfer of stock during the supplier lead time (which affects inventory positions). Stock transfers during the supplier lead time would essentially change the random variable $X_{i}$ (and its distribution function $H_{i}(x)$ ) in Equation (4), making the computation of the average cost per period very difficult, if not impossible. Therefore, for approximating the average cost per period of the multicycle problem by using (5), we propose an order adjustment rule (details presented below), at the expense of an assumption on the order quantities. The order adjustment rule states that the retailer orders that are outstanding at the supplier can be modified (without changing the total order size) dynamically.

Assume that the periods are numbered $0,1,2, \ldots$ and assume a supplier lead time $L \in\{1,2, \ldots\}$. We assume that the following sequence of events occurs for every period $t$ :

(1) Orders placed in period $t-L$ arrive at the crossdocking warehouse, ready to be shipped to retailers,

(2) State of the system is observed,

(3) A possible transfer of stock is realized,

(4) Orders arrive at the retailers (this allows the possibility that $l_{i}=0$; in that case, right after a possible transfer of stock at the cross-docking warehouse the possibly modified order arrives at retailer $i$ ),

(5) Each retailer places its order at the supplier,

(6) Demand occurs, and

(7) Holding and backorder costs are incurred at the retailers.

Let $S_{1}$ and $S_{2}$ be stationary order-up-to levels for retailers 1 and 2, respectively. We use the following additional notation to facilitate the presentation.

- $I_{i, t}$ : "Partial" inventory position of retailer $i$ in period $t$ right before a possible transfer of stock. The "partial" inventory position of retailer $i$ in a period $t$ is defined as the on-hand stock minus backorders plus the orders that will arrive at the retailer in periods $t, t+1, \ldots, t+l_{i}$. This includes the order just made ready at the cross-docking warehouse, and the orders in the pipeline between the warehouse and the retailer. However, the outstanding orders at the crossdocking warehouse are excluded. 
- $I_{i, t}^{\prime}:$ "Partial" inventory position of retailer $i$ in period $t$ right after a possible transfer of stock.

- $\eta_{i, t}$ : Amount transferred from retailer $j \neq i$ to retailer $i$ in period $t$.

- $O_{i, t, s}:$ Status in period $s$ of the order placed by retailer $i$ in period $t, s=t, \ldots, t+L-1 . O_{i, t, t}$ is the size of the order placed in period $t$ by retailer $i$. When $L \geq 2$, we allow that the order placed by the retailer can be modified in later periods. Consequently, let $O_{i, t, t+1}, \ldots, O_{i, t, t+L-1}$ denote the sizes after a possible change in the periods $t+1, \ldots, t+L-1$.

- $D_{i, t}$ : Demand at retailer $i$ in period $t$.

We also define a "complete" inventory position, which is the on-hand stock minus backorders plus all goods that are on order, including the orders outstanding at the warehouse. Notice that for $L=1$, the "partial" and "complete" inventory position right before a possible transfer of stock are identical. Without loss of generality, we assume that the initial "complete" inventory position of retailer $i$ does not exceed $S_{i}$. The state of the system at the beginning period $t=0,1, \ldots$, right before a possible transfer of stock, is described by the vector

$$
\begin{aligned}
& \left(I_{1, t}, O_{1, t-L+1, t-1}, \ldots, O_{1, t-1, t-1},\right. \\
& \left.I_{2, t}, O_{2, t-L+1, t-1}, \ldots, O_{2, t-1, t-1}\right),
\end{aligned}
$$

provided that at time $t=0, I_{i, 0}$ and $O_{i, s,-1}$ are given for $i=1,2$, and $s=-L+1, \ldots,-1$. For $L=1$, the state of the system reduces to $\left(I_{1, t}, I_{2, t}\right)$. Note that $O_{i, t-L+1, t-1}$ is the status (after possible modifications), at the end of period $t-1$, of the order placed by retailer $i$ in period $t-L+1$. This order is because of the arrival at the cross-docking warehouse at the beginning of period $t+1$. For $t=0,1, \ldots$, after the orders placed by the retailers in period $t-L\left(O_{1, t-L, t-1}\right.$ and $O_{2, t-L, t-1}$ ) arrive at the warehouse (Step 1 in the event list), and after the state of the system is observed (Step 2 in the event list), a possible transfer of stock occurs by the amounts

$$
\begin{aligned}
& \eta_{1, t}=\min \left\{\left(I_{2, t}-Z_{2}\right)^{+},\left(Z_{1}-I_{1, t}\right)^{+}\right\}, \\
& \eta_{2, t}=\min \left\{\left(I_{1, t}-Z_{1}\right)^{+},\left(Z_{2}-I_{2, t}\right)^{+}\right\},
\end{aligned}
$$

which changes inventory positions of retailers to posttransfer levels,

$$
\begin{aligned}
& I_{1, t}^{\prime}=I_{1, t}+\eta_{1, t}-\eta_{2, t} . \\
& I_{2, t}^{\prime}=I_{2, t}+\eta_{2, t}-\eta_{1, t} .
\end{aligned}
$$

Equations (6)-(9) are valid under the assumption that orders $O_{1, t-L, t-1}$ and $O_{2, t-L, t-1}$ being present at the warehouse at the moment are large enough. This assumption is similar to the "sufficient stock" assumption, commonly employed in multiechelon inventory theory (see, for example, Eppen and Schrage 1981). The sufficient stock assumption ensures that there is enough stock (say, $O_{1, t-L, t-1}$ ) to realize the transfer of stock. We state our main result regarding the stationary problem in Lemma 1.

Lemma 1. The average cost per period of a retailer in a multiple order cycle setting is obtained by the expected cost of a single cycle (given by Equation (4)) under the assumption that order sizes are always sufficient to ensure feasibility of a stock transfer (the sufficient stock assumption described above).

Proof. It is sufficient to show that for any $t=$ $1,2, \ldots$, "partial" inventory positions of a retailer, right before and after the transfer of stock (that is, $I_{i, t}$ and $\left.I_{i, t}^{\prime}\right)$ are given by $I_{i, t}=S_{i}-D_{i}(L)$ and $I_{i, t}^{\prime}=$ $S_{i}-X_{i}$. We distinguish the cases $L=1$ and $L \geq 2$. We first consider the case $L=1$. By the orders placed in a period $t-1$, the "complete" inventory positions of the retailers are increased up to the order-up-to levels $S_{i}$ (this is always possible), and in period $t$, we obtain "partial" inventory positions right after a possible transfer of stock as given by Equations (8) and (9). These inventory positions determine the costs for retailer $i$ at the end of period $t+l_{i}, i=1,2$. It is easily verified that, in expectation, these costs are equal to the costs $C_{i}\left(S_{1}, S_{2}\right)$ as described in the singlecycle analysis in \$3.2, Equation (4) $\left(I_{i, t}=S_{i}-D_{i, t-1}\right.$, and thus $\eta_{i, t}$ is stochastically equal to $\eta_{i}$ of the single cycle analysis). So the single cycle analysis applies in this case. The more complicated case $L \geq 2$ is presented in the appendix.

\section{Distribution of the Net Change in Inventory Position}

As stated by Equation (5), if we can derive the distribution of $X_{i}$, then the expected cost functions possibly the optimal policy parameters can be obtained. Proposition 2 characterizes the distribution function for $X_{i}$. 
Proposition 2. The distribution function of $X_{1}$ has the following form:

$$
H_{1}(x)=\left\{\begin{array}{rr}
\int_{0}^{x} F_{2}^{(L)}\left(\Delta_{2}+x-y\right) f_{1}^{(L)}(y) d y & x<\Delta_{1}, \\
F_{1}^{(L)}(x)+\int_{x}^{x+\Delta_{2}} F_{2}^{(L)}\left(\Delta_{2}+x-y\right) f_{1}^{(L)}(y) d y & x \geq \Delta_{1} .
\end{array}\right.
$$

Proof. The result is established by first conditioning on $D_{1}(L)$ and then by using the distributions of $A_{i}$ and $B_{i}$. Details are provided in the appendix.

The distribution of $\mathrm{X}_{2}, \mathrm{H}_{2}(x)$, is symmetric and obtained by interchanging indices 1 and 2 wherever possible in Proposition 2. For simplifying the notation we define

$$
\begin{gathered}
R_{11}(x)=\int_{0}^{x} F_{2}^{(L)}\left(\Delta_{2}+x-y\right) f_{1}^{(L)}(y) d y, \\
R_{12}(x)=F_{1}^{(L)}(x)+\int_{x}^{x+\Delta_{2}} F_{2}^{(L)}\left(\Delta_{2}+x-y\right) f_{1}^{(L)}(y) d y,
\end{gathered}
$$

so that $H_{1}(x)=R_{11}(x)$ on $x<\Delta_{1}$ and $H_{1}(x)=R_{12}(x)$ otherwise. Let $r_{11}(x)$ and $r_{12}(x)$ be the derivatives of $R_{11}(x)$ and $R_{12}(x)$, respectively $\left(r_{11}(x)\right.$ and $r_{12}(x)$ are well defined by the assumptions imposed on $\left.F_{1}^{(1)}(x)\right)$.

Closer inspection of $H_{1}(x)$ reveals that $H_{1}(x)$ is continuous for $x<\Delta_{1}$ and $x>\Delta_{1}$, but has a jump at $x=\Delta_{1}$ with probability

$$
\begin{aligned}
P_{1}\left(\Delta_{1}\right)= & R_{12}\left(\Delta_{1}\right)-R_{11}\left(\Delta_{1}\right) \\
= & \int_{\Delta_{1}}^{\Delta_{1}+\Delta_{2}} F_{2}^{(L)}\left(\Delta_{2}+\Delta_{1}-y\right) f_{1}^{(L)}(y) d y \\
& +\int_{0}^{\Delta_{1}}\left(1-F_{2}^{(L)}\left(\Delta_{2}+\Delta_{1}-y\right)\right) f_{1}^{(L)}(y) d y .
\end{aligned}
$$

The jump at $x=\Delta_{1}$ characterizes the probability mass for which retailer 1 can achieve its best $\left(l_{1}+1\right)$-period order-up-to level $Z_{1}$ through transfer of retailer orders at the cross-docking warehouse. We note that the sum $P\left(\Delta_{1}, \Delta_{2}\right)=P_{1}\left(\Delta_{1}\right)+P_{2}\left(\Delta_{2}\right)$ gives the probability that a transfer of stock occurs between retailers 1 and 2 . It can easily be shown that this probability can be rewritten as

$$
\begin{aligned}
& P\left(\Delta_{1}, \Delta_{2}\right) \\
& \quad=F_{1}^{(L)}\left(\Delta_{1}\right)\left(1-F_{2}^{(L)}\left(\Delta_{2}\right)\right)+F_{2}^{(L)}\left(\Delta_{2}\right)\left(1-F_{1}^{(L)}\left(\Delta_{1}\right)\right) .
\end{aligned}
$$

This is simply the probability that one retailer will be above and the other retailer will be below their corresponding ideal stocking points. If retailers are identical; that is, $F_{1}^{(L)}\left(\Delta_{1}\right)=F_{2}^{(L)}\left(\Delta_{2}\right)$, then the probability that a transfer of stock occurs cannot exceed 0.5 (in this case, $P\left(\Delta_{1}, \Delta_{2}\right)$ is concave and attains its maximum at 0.5$)$.

Limiting cases for $H_{1}(x)$ can be obtained by letting $\Delta_{2} \rightarrow \infty$ (ample stock in retailer 2, that can be used to satisfy any shortfall of retailer 1) and for $\Delta_{2}=0$ (retailer 2 is willing to receive any excess of retailer 1 ).

In deriving $H_{i}(x)$, we assumed that the demands occurring at retailers 1 and 2 are independent. This restriction can easily be relaxed. When retailer demands are correlated, $H_{1}(x)$ is affected only through conditional distribution of $D_{2}(L)$. Define $F_{2}^{(L)}(x \mid y)$ as the distribution of $D_{2}(L)$ conditioned on $D_{1}(L)=y$. Then, using similar steps as in proof of Proposition 2, we can obtain

$$
H_{1}(x)=\left\{\begin{array}{lr}
\int_{0}^{x} F_{2}^{(L)}\left(\Delta_{2}+x-y \mid y\right) f_{1}^{(L)}(y) d y & x<\Delta_{1}, \\
F_{1}^{(L)}(x)+\int_{x}^{x+\Delta_{2}} F_{2}^{(L)}\left(\Delta_{2}+x-y \mid y\right) f_{1}^{(L)}(y) d y & x \geq \Delta_{1} .
\end{array}\right.
$$

\section{Equilibrium Order-up-to Levels Under Transfer of Stock}

In $\$ 3.2$, we argued that the expected cost function of retailer $i$ can be written as $C_{i}\left(S_{1}, S_{2}\right)=\int_{0}^{\infty} G_{i}\left(S_{i}-\right.$ $\left.X_{i}\right) d H_{i}(x)$, where $H_{i}(x)$ is given by Proposition 2 . Given that there is an opportunity of stock transfer at the cross-docking warehouse, the retailers would determine their initial order-up-to levels $S_{1}$ and $S_{2}$ by considering the order-up-to level decision of each other. Our aim in this section is to show the existence of the unique equilibrium.

We can outline major results that we present in this section as follows: By Theorem 1.2 of Fudenberg and Tirole (1991), a Nash equilibrium for retailers 1 and 2 exists whenever (1) the action space for retailers (that is, set of values $\left.\left(S_{1}, S_{2}\right)\right)$ is nonempty and compact, (2) $C_{i}\left(S_{1}, S_{2}\right)$ is continuous in $\left(S_{1}, S_{2}\right)$, and (3) $C_{i}\left(S_{1}, S_{2}\right)$ is convex in $S_{i}$ for a given $S_{j}(j \neq i)$. In Theorem 1 , we establish continuity and convexity of $C_{i}\left(S_{1}, S_{2}\right)$ on a compact subset of $R^{2}$. This proves the existence of a Nash solution. In Theorem 2, we provide the solution for the unique Nash equilibrium. 
THEorem 1. (i) $C_{i}\left(S_{1}, S_{2}\right)$ is continuous in $\left(S_{1}, S_{2}\right)$ on the action space $\Omega=\left[Z_{1}, \widetilde{S}_{1}\right] \times\left[Z_{2}, \widetilde{S}_{2}\right]$, where $\widetilde{S}_{i}$ is obtained by solving $F_{j}^{(L)} * F_{i}^{\left(L+l_{i}+1\right)}\left(\widetilde{S}_{i}\right)=b_{i} /\left(b_{i}+h_{i}\right), i, j=$ $1,2, i \neq j$.

(ii) $C_{i}\left(S_{1}, S_{2}\right)$ is strictly convex in $S_{i}$ for a given value of $S_{j}, i, j=1,2, i \neq j$.

(iii) The optimal order-up-to level for retailer $i$ $(i=1,2), S_{i}^{*}\left(S_{j}\right)$ for a given $S_{j}(j \neq i)$, can be obtained by solving

$$
\begin{aligned}
U_{i}\left(S_{1}, S_{2}\right) & :=\frac{\partial C_{i}\left(S_{1}, S_{2}\right)}{\partial S_{i}}=\int_{0}^{\infty} G_{i}^{\prime}\left(S_{i}-w\right) d H_{i}(w) \\
& =-b_{i}+\left(h_{i}+b_{i}\right) H_{i} * F_{i}^{\left(l_{i}+1\right)}\left(S_{i}\right)=0 .
\end{aligned}
$$

Proof. The proof is provided in the appendix.

Theorem 2. Optimal order-up-to levels for the retailers, $\left(S_{1}^{*}, S_{2}^{*}\right)$, is found as the unique solution of the following equations:

$$
\begin{aligned}
& H_{1} * F_{1}^{\left(l_{1}+1\right)}\left(S_{1}\right)=\frac{b_{1}}{b_{1}+h_{1}}, \\
& H_{2} * F_{2}^{\left(l_{2}+1\right)}\left(S_{2}\right)=\frac{b_{2}}{b_{2}+h_{2}} .
\end{aligned}
$$

Proof. The proof is provided in the appendix.

\section{Computational Results}

In this section, we present and discuss our numerical findings. Our main focus of inquiry will span

(1) the behavior of the equilibrium solution (given by Theorem 2) and corresponding expected costs with respect to essential system parameters,

(2) improvement of the proposed model (in terms of costs and safety stocks) relative to the decentralized model without stock transfer, and

(3) system performance relative to centralized model.

In our numerical study, the random demand faced by retailer $i$ in a period is normally distributed with mean $\mu_{i}$ and variance $\sigma_{i}^{2}$. We set $h_{1}=h_{2}=1$ and use $b_{1}=b_{2} \in\{4,9,19\}$ (corresponding to service levels $\{0.8,0.9,0.95\})$, respectively. The mean demand for retailer 1 is fixed at $\mu_{1}=100$, and $\mu_{2}$ is set to either 100 or 200. We let $c v_{i}=\sigma_{i} / \mu_{i}$ to assume either 0.05 or 0.25 , $i=1,2$. The supplier lead time is set to $L=5$, and the retailer lead time takes either $l_{i}=1$ or $l_{i}=3$ for $i=1,2$. We used numerical integration procedures of
Maple 8 for solving the optimal order-up-to levels and evaluating expected costs.

Through our experiments, we computed and recorded the following policy parameters and performance measures:

- $S_{i}^{\text {ind }}$ : Order-up-to level for retailer $i$, given that they place their orders independently, without the possibility of stock transfer. $S_{i}^{\text {ind }}$ is found from Equation (11).

$$
F_{i}^{\left(L+l_{i}+1\right)}\left(S_{i}^{\text {ind }}\right)=\frac{b_{i}}{b_{i}+h_{i}}
$$

- $C_{i}^{\text {ind }}$ : Expected cost incurred by retailer $i$ if it operates with the order-up-to level $S_{i}^{\text {ind }}$

$$
\begin{aligned}
C_{i}^{\text {ind }}= & h_{i} E\left[\left(S_{i}^{\text {ind }}-D_{i}\left(L+l_{i}+1\right)\right)^{+}\right] \\
& +b_{i} E\left[\left(D_{i}\left(L+l_{i}+1\right)-S_{i}^{\text {ind }}\right)^{+}\right] .
\end{aligned}
$$

- $S_{i}^{*}$ : Order-up-to level for retailer $i$ under proposed model (given by Theorem 2).

- $Z_{i}$ : Order-up-to level for retailer $i$ over the retailer lead time (given by Equation (2)).

- $C_{i}\left(S_{1}^{*}, S_{2}^{*}\right)$ : Minimum expected cost incurred at retailer $i$ under proposed model (given by Equation (5)).

- $\% C_{i}$ : Percentage improvement gained for retailer $i$ over the decentralized model

$$
\% C_{i}=\frac{C_{i}^{\text {ind }}-C_{i}\left(S_{1}^{*}, S_{2}^{*}\right)}{C_{i}^{\text {ind }}} \times 100 .
$$

- \%TC: Percent improvement gained over the total cost of the decentralized model

$$
\% T C=\frac{\sum_{i} C_{i}^{\text {ind }}-\sum_{i} C_{i}\left(S_{1}^{*}, S_{2}^{*}\right)}{\sum_{i} C_{i}^{\text {ind }}} \times 100
$$

- The safety stock for retailer $i$ under decentralized model with stock transfer can be defined as $S S_{i}=S_{i}^{*}-$ $\left(L+l_{i}+1\right) \mu_{i}$. Similarly, $S S_{i}^{\text {ind }}=S_{i}^{\text {ind }}-\left(L+l_{i}+1\right) \mu_{i}$ is the safety stock for retailer $i$ for the decentralized model without stock transfer. Then, the percentage reduction in terms of safety stocks can be calculated as

$$
\% S S_{i}=\frac{S_{i}^{\text {ind }}-S_{i}^{*}}{S_{i}^{\text {ind }}-\left(L+l_{i}+1\right) \mu_{i}} \times 100 .
$$

Similarly, total safety stock improvement is calculated as

$$
\% S S=\frac{\sum_{i} S_{i}^{i n d}-\sum_{i} S_{i}^{*}}{\sum_{i} S_{i}^{\text {ind }}-\sum_{i}\left(L+l_{i}+1\right) \mu_{i}} \times 100 .
$$


Table 1 Summary Results for Identical Retailers

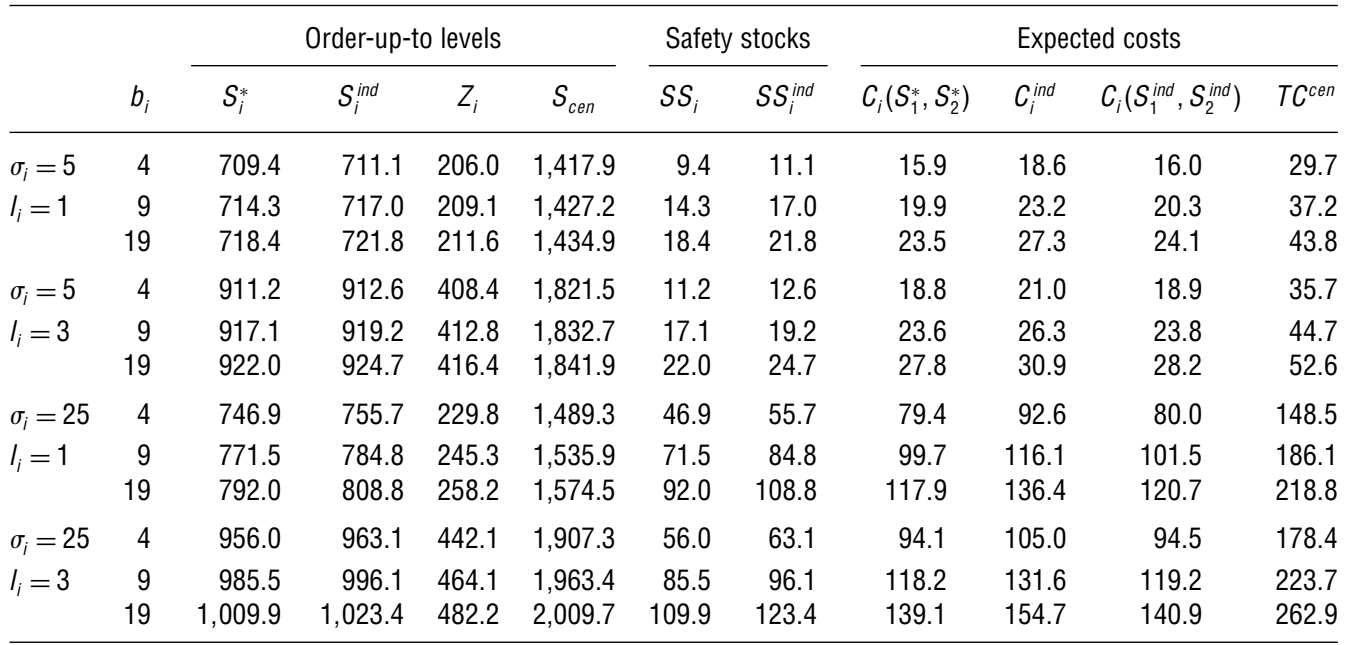

- $P\left(\Delta_{1}, \Delta_{2}\right)$ : Probability that a transfer of stock occurs between retailers.

In $\S 6.1$, we present our major observations regarding the behavior of the performance measures and the improvement of the model that we propose over the decentralized model. In $\S 6.2$, we present comparisons with the centralized model. Finally, in §6.3, we investigate the benefits that would be observed if retailers operate with the order-up-to levels dictated by the decentralized model, but apply transfer of stock.

Table 1 summarizes our computational results for symmetric retailers $\left(\mu_{1}=\mu_{2}=100, \sigma_{1}=\sigma_{2} \in\{5,25\}\right.$, $\left.b_{1}=b_{2} \in\{4,9,19\}, l_{1}=l_{2} \in\{1,3\}\right)$. In Table 2, we present several percent measures for the performance of the proposed model. Columns for \%SS and \%TC

Table 2 Performance of the Proposed Policy for Identical Retailers

\begin{tabular}{lrrrrrrr}
\hline & $b_{i}$ & $\% S S$ & $\% S S_{\text {cen }}$ & $\% T C$ & $\% P O L$ & $\% D$ & $\% B$ \\
\hline$\sigma_{i}=5$ & 4 & 16.0 & 4.8 & 14.4 & 95.2 & 6.9 & 72.2 \\
$l_{i}=1$ & 9 & 15.5 & 5.4 & 14.1 & 89.1 & 7.2 & 70.8 \\
& 19 & 15.2 & 5.7 & 13.9 & 83.0 & 7.3 & 70.4 \\
$\sigma_{i}=5$ & 4 & 11.3 & 4.4 & 10.4 & 96.4 & 5.5 & 69.1 \\
$I_{i}=3$ & 9 & 11.1 & 4.6 & 10.2 & 92.5 & 5.7 & 67.7 \\
& 19 & 11.0 & 4.7 & 10.1 & 88.0 & 5.8 & 67.4 \\
$\sigma_{i}=25$ & 4 & 15.8 & 5.0 & 14.3 & 95.1 & 6.9 & 72.0 \\
$l_{i}=1$ & 9 & 15.6 & 5.3 & 14.1 & 89.1 & 7.2 & 71.0 \\
& 19 & 15.4 & 5.5 & 13.6 & 84.8 & 7.8 & 68.6 \\
$\sigma_{i}=25$ & 4 & 11.3 & 4.4 & 10.3 & 96.6 & 5.5 & 68.7 \\
$l_{i}=3$ & 9 & 11.1 & 4.7 & 10.2 & 92.4 & 5.6 & 68.1 \\
& 19 & 10.9 & 4.9 & 10.1 & 88.2 & 5.8 & 67.3 \\
\hline
\end{tabular}

would give us percent improvement in safety stocks and expected total costs over the decentralized model, respectively. In Tables 3 and 4, we present our results for unidentical retailers. As the number of such cases is large, we present a representative subset $\left(\mu_{1}=100\right.$, $\left.\mu_{2}=200, b_{1}=b_{2}=4\right)$. Some of the columns in the tables will subsequently be explained. Tables containing all the computational results can be provided by the authors upon request.

\subsection{Main Observations}

Main observations drawn from our experiments can be summarized as follows:

(1) For the parameter set that we use, we always observed that $C_{i}\left(S_{1}^{*}, S_{2}^{*}\right)<C_{i}^{\text {ind }}$ and $S_{i}^{*}<S_{i}^{\text {ind }}$ for $i=$ 1,2 . Percent cost improvement gained by employing the proposed model, $\% C_{i}$, can be as high as $22 \%$ for a retailer (see Table 4). On the other hand, total cost improvement over the decentralized model without stock transfer, $\% T C$, can be as high as $14 \%$ (see Table 2). Percent improvement in the safety stocks for a retailer, $\% S S_{i}$, can be as high as $33 \%$ (see Table 3). Similarly, total safety stock improvement can be as high as $16 \%$. Please note that in Table 2, columns corresponding to \%TC and \%SS would also give us improvements for individual retailers, as in these cases retailers are identical.

(2) We observe that as $\sigma_{1}$ gets close to $\sigma_{2}$, $\% T C$ increases. Intuitively, given that one retailer ends up above and the other retailer ends up below its respective $Z_{i}$ value at the end of supplier lead time, 
Table 3 Stocking Levels and Percent Improvements for $\mu_{1}=100, \mu_{2}=200, b_{1}=b_{2}=4$

\begin{tabular}{|c|c|c|c|c|c|c|c|c|c|c|c|c|c|c|}
\hline & \multirow[b]{2}{*}{$\left(I_{1}, I_{2}\right)$} & \multicolumn{6}{|c|}{ Order-up-to levels } & \multicolumn{4}{|c|}{ Safety stocks } & \multicolumn{3}{|c|}{$\begin{array}{c}\text { Percent } \\
\text { improvements }\end{array}$} \\
\hline & & $S_{1}^{*}$ & $S_{2}^{*}$ & $S_{1}^{\text {ind }}$ & $S_{2}^{\text {ind }}$ & $Z_{1}$ & $Z_{2}$ & $S S_{1}$ & $S S_{2}$ & $S S_{1}^{\text {ind }}$ & $S S_{2}^{\text {ind }}$ & $\% S S_{1}$ & $\% S S_{2}$ & $\% S S$ \\
\hline$\sigma_{1}=5$ & $(1,1)$ & 708.5 & $1,420.2$ & 711.1 & $1,422.3$ & 206.0 & 411.9 & 8.5 & 20.2 & 11.1 & 22.3 & 23.4 & 9.1 & 13.9 \\
\hline$\sigma_{2}=10$ & $\begin{array}{l}(1,3) \\
(3,1) \\
(3,3)\end{array}$ & $\begin{array}{l}709.0 \\
910.1 \\
910.2\end{array}$ & $\begin{array}{l}1,823.2 \\
1,420.6 \\
1,823.8\end{array}$ & $\begin{array}{l}711.1 \\
912.6 \\
912.6\end{array}$ & $\begin{array}{l}1,825.2 \\
1,422.3 \\
1,825.2\end{array}$ & $\begin{array}{l}206.0 \\
408.4 \\
408.4\end{array}$ & $\begin{array}{l}816.8 \\
411.9 \\
816.8\end{array}$ & $\begin{array}{r}9.0 \\
10.1 \\
10.2\end{array}$ & $\begin{array}{l}23.2 \\
20.6 \\
23.8\end{array}$ & $\begin{array}{l}11.1 \\
12.6 \\
12.6\end{array}$ & $\begin{array}{l}25.2 \\
22.3 \\
25.2\end{array}$ & $\begin{array}{l}18.7 \\
20.0 \\
19.1\end{array}$ & $\begin{array}{l}8.2 \\
7.3 \\
5.9\end{array}$ & $\begin{array}{l}11.4 \\
11.9 \\
10.3\end{array}$ \\
\hline$\sigma_{1}=5$ & $(1,1)$ & 707.4 & $1,509.2$ & 711.1 & $1,511.3$ & 206.0 & 459.5 & 7.4 & 109.2 & 11.1 & 111.3 & 33.4 & 1.9 & 4.8 \\
\hline$\sigma_{2}=50$ & $\begin{array}{l}(1,3) \\
(3,1) \\
(3,3)\end{array}$ & $\begin{array}{l}708.1 \\
909.1 \\
909.9\end{array}$ & $\begin{array}{l}1,926.2 \\
1,509.6 \\
1,924.4\end{array}$ & $\begin{array}{l}711.1 \\
912.6 \\
912.6\end{array}$ & $\begin{array}{l}1,926.2 \\
1,511.3 \\
1,926.2\end{array}$ & $\begin{array}{l}206.0 \\
408.4 \\
408.4\end{array}$ & $\begin{array}{l}884.2 \\
459.5 \\
884.2\end{array}$ & $\begin{array}{l}8.1 \\
9.1 \\
9.9\end{array}$ & $\begin{array}{l}126.2 \\
109.6 \\
124.4\end{array}$ & $\begin{array}{l}11.1 \\
12.6 \\
12.6\end{array}$ & $\begin{array}{l}126.2 \\
111.3 \\
126.2\end{array}$ & $\begin{array}{l}27.1 \\
27.9 \\
21.8\end{array}$ & $\begin{array}{l}0.0 \\
1.6 \\
1.5\end{array}$ & $\begin{array}{l}2.2 \\
4.3 \\
3.3\end{array}$ \\
\hline$\sigma_{1}=25$ & $(1,1)$ & 751.4 & $1,416.8$ & 755.7 & $1,422.3$ & 229.8 & 411.9 & 51.4 & 16.8 & 55.7 & 22.3 & 7.7 & 24.5 & 12.5 \\
\hline$\sigma_{2}=10$ & $\begin{array}{l}(1,3) \\
(3,1) \\
(3,3)\end{array}$ & $\begin{array}{l}752.2 \\
958.8 \\
959.6\end{array}$ & $\begin{array}{l}1,819.9 \\
1,417.9 \\
1,821.0\end{array}$ & $\begin{array}{l}755.7 \\
963.1 \\
963.1\end{array}$ & $\begin{array}{l}1,825.2 \\
1,422.3 \\
1,825.2\end{array}$ & $\begin{array}{l}229.8 \\
442.1 \\
442.1\end{array}$ & $\begin{array}{l}816.8 \\
411.9 \\
816.8\end{array}$ & $\begin{array}{l}52.2 \\
58.8 \\
59.6\end{array}$ & $\begin{array}{l}19.9 \\
17.9 \\
21.0\end{array}$ & $\begin{array}{l}55.7 \\
63.1 \\
63.1\end{array}$ & $\begin{array}{l}25.2 \\
22.3 \\
25.2\end{array}$ & $\begin{array}{l}6.1 \\
6.9 \\
5.5\end{array}$ & $\begin{array}{l}21.1 \\
19.6 \\
16.9\end{array}$ & $\begin{array}{r}10.8 \\
10.2 \\
8.8\end{array}$ \\
\hline$\sigma_{1}=25$ & $(1,1)$ & 742.9 & $1,501.2$ & 755.7 & $1,511.3$ & 229.8 & 459.5 & 42.9 & 101.2 & 55.7 & 111.3 & 22.9 & 9.1 & 13.7 \\
\hline$\sigma_{2}=50$ & $\begin{array}{l}(1,3) \\
(3,1) \\
(3,3)\end{array}$ & $\begin{array}{l}745.5 \\
950.7 \\
953.2\end{array}$ & $\begin{array}{l}1,915.9 \\
1,503.2 \\
1,917.9\end{array}$ & $\begin{array}{l}755.7 \\
963.1 \\
963.1\end{array}$ & $\begin{array}{l}1,926.2 \\
1,511.3 \\
1,926.2\end{array}$ & $\begin{array}{l}229.8 \\
442.1 \\
442.1\end{array}$ & $\begin{array}{l}884.2 \\
459.5 \\
884.2\end{array}$ & $\begin{array}{l}45.5 \\
50.7 \\
53.2\end{array}$ & $\begin{array}{l}115.9 \\
103.2 \\
117.9\end{array}$ & $\begin{array}{l}55.7 \\
63.1 \\
63.1\end{array}$ & $\begin{array}{l}126.2 \\
111.3 \\
126.2\end{array}$ & $\begin{array}{l}18.2 \\
19.7 \\
15.8\end{array}$ & $\begin{array}{l}8.2 \\
7.3 \\
6.6\end{array}$ & $\begin{array}{r}11.3 \\
11.8 \\
9.6\end{array}$ \\
\hline
\end{tabular}

respective excess and shortfall quantities will be close to each other. Therefore the likelihood that both of the retailers will get close to their respective $Z_{i}$ values will increase. We observe the same behavior for the safety stock improvements. Our model leads to higher improvements in total safety stocks whenever retailers are more symmetric. Consequently, highest values for total improvement (\%TC or $\% S S$ ) can be observed in Table 2.

On the other hand, highest improvement in the expected cost of a retailer, $\% C_{i}$, occurs when retailers are highly unbalanced (for example, $\% C_{1}=22.4 \%$ and $\% C_{2}=2.5 \%$ for $\mu_{1}=100, \mu_{2}=200, \sigma_{1}=5, \sigma_{2}=50$, $b_{1}=b_{2}=4, l_{1}=l_{2}=1$ in Table 4). Moreover, in these

Table 4 Expected Costs and Percent Improvements for $\mu_{1}=100, \mu_{2}=200, b_{1}=b_{2}=4$

\begin{tabular}{|c|c|c|c|c|c|c|c|c|c|c|}
\hline & \multirow[b]{2}{*}{$\left(I_{1}, I_{2}\right)$} & \multicolumn{6}{|c|}{ Expected costs } & \multicolumn{3}{|c|}{$\begin{array}{c}\text { Percent } \\
\text { improvements }\end{array}$} \\
\hline & & $C_{1}\left(S_{1}^{*}, S_{2}^{*}\right)$ & $C_{2}\left(S_{1}^{*}, S_{2}^{*}\right)$ & $C_{1}^{\text {ind }}$ & $C_{2}^{\text {ind }}$ & $C_{1}\left(S_{1}^{\text {ind }}, S_{2}^{\text {ind }}\right)$ & $C_{2}\left(S_{1}^{\text {ind }}, S_{2}^{\text {ind }}\right)$ & $\% C_{1}$ & $\% C_{2}$ & $\% T C$ \\
\hline$\sigma_{1}=5$ & $(1,1)$ & 15.1 & 33.5 & 18.5 & 37.0 & 15.4 & 33.5 & 18.2 & 9.5 & 12.4 \\
\hline$\sigma_{2}=10$ & $\begin{array}{l}(1,3) \\
(3,1) \\
(3,3)\end{array}$ & $\begin{array}{l}15.2 \\
18.2 \\
18.2\end{array}$ & $\begin{array}{l}39.0 \\
33.5 \\
39.1\end{array}$ & $\begin{array}{l}18.5 \\
21.0 \\
21.0\end{array}$ & $\begin{array}{l}42.0 \\
37.0 \\
42.0\end{array}$ & $\begin{array}{l}15.4 \\
18.4 \\
18.4\end{array}$ & $\begin{array}{l}39.0 \\
33.6 \\
39.1\end{array}$ & $\begin{array}{l}18.0 \\
13.3 \\
13.1\end{array}$ & $\begin{array}{l}7.1 \\
9.5 \\
7.0\end{array}$ & $\begin{array}{r}10.4 \\
10.9 \\
9.0\end{array}$ \\
\hline$\sigma_{1}=5$ & $(1,1)$ & 14.4 & 180.6 & 18.5 & 185.2 & 14.7 & 180.3 & 22.4 & 2.5 & 4.3 \\
\hline$\sigma_{2}=50$ & $\begin{array}{l}(1,3) \\
(3,1) \\
(3,3)\end{array}$ & $\begin{array}{l}14.4 \\
17.6 \\
17.6\end{array}$ & $\begin{array}{l}206.1 \\
180.6 \\
206.1\end{array}$ & $\begin{array}{l}18.5 \\
21.0 \\
21.0\end{array}$ & $\begin{array}{l}210.0 \\
185.2 \\
210.0\end{array}$ & $\begin{array}{l}14.7 \\
17.9 \\
17.8\end{array}$ & $\begin{array}{l}205.8 \\
180.4 \\
206.0\end{array}$ & $\begin{array}{l}22.1 \\
16.2 \\
16.0\end{array}$ & $\begin{array}{l}1.8 \\
2.5 \\
1.8\end{array}$ & $\begin{array}{l}3.5 \\
3.9 \\
3.1\end{array}$ \\
\hline$\sigma_{1}=25$ & $(1,1)$ & 85.0 & 29.9 & 92.6 & 37.0 & 85.0 & 30.5 & 8.1 & 19.2 & 11.3 \\
\hline$\sigma_{2}=10$ & $\begin{array}{l}(1,3) \\
(3,1) \\
(3,3)\end{array}$ & $\begin{array}{l}85.1 \\
98.6 \\
98.7\end{array}$ & $\begin{array}{l}36.1 \\
30.0 \\
36.2\end{array}$ & $\begin{array}{r}92.6 \\
105.0 \\
105.0\end{array}$ & $\begin{array}{l}42.0 \\
37.0 \\
42.0\end{array}$ & $\begin{array}{l}85.1 \\
98.6 \\
98.7\end{array}$ & $\begin{array}{l}36.6 \\
30.4 \\
36.5\end{array}$ & $\begin{array}{l}8.1 \\
6.1 \\
6.0\end{array}$ & $\begin{array}{l}14.0 \\
18.9 \\
13.8\end{array}$ & $\begin{array}{l}9.9 \\
9.4 \\
8.2\end{array}$ \\
\hline$\sigma_{1}=25$ & $(1,1)$ & 75.7 & 167.5 & 92.6 & 185.2 & 77.0 & 167.6 & 18.2 & 9.5 & 12.4 \\
\hline$\sigma_{2}=50$ & $\begin{array}{l}(1,3) \\
(3,1) \\
(3,3)\end{array}$ & $\begin{array}{l}75.9 \\
91.0 \\
91.2\end{array}$ & $\begin{array}{l}195.1 \\
167.7 \\
195.3\end{array}$ & $\begin{array}{r}92.6 \\
105.0 \\
105.0\end{array}$ & $\begin{array}{l}210.0 \\
185.2 \\
210.0\end{array}$ & $\begin{array}{l}76.8 \\
92.0 \\
91.9\end{array}$ & $\begin{array}{l}195.2 \\
167.8 \\
195.4\end{array}$ & $\begin{array}{l}18.0 \\
13.3 \\
13.1\end{array}$ & $\begin{array}{l}7.1 \\
9.5 \\
7.0\end{array}$ & $\begin{array}{r}10.4 \\
10.9 \\
9.0\end{array}$ \\
\hline
\end{tabular}


cases, we observed that the retailer with lower standard deviation of demand gains higher improvement. In Table 4 , retailer 1 gains relatively higher improvement as $\sigma_{1} / \sigma_{2}$ ratio decreases. Similarly, as one would expect, these cases also coincide with the cases where one of the retailers gain high saving in terms of safety stocks (for the example above, $\% S S_{1}=33.4 \%, \% S S_{2}=$ $1.9 \%)$, as observed in Table 3. The retailer with higher standard deviation of demand is expected to show higher deviation from its $Z_{i}$ value at the end of the supplier lead time. Consequently, the retailer with lower standard deviation has a higher chance of correcting its shortfall or excess by transfer of stock from the former, and hence can retain lower stock levels.

(3) We observed that the amount of improvement in safety stocks or total costs mainly depends on the relative variability between retailers, rather than the absolute value of variabilities. In Table 2, we observe that the rows corresponding to $\sigma_{i}=5$ and $\sigma_{i}=25$ are almost identical with respect to $\% S S$ and $\% T C$. Similarly, in Tables 3 and 4 rows corresponding to cases $\sigma_{1}=5, \sigma_{2}=10$ and $\sigma_{1}=25, \sigma_{2}=50$ yield almost identical $\% C_{i}$ and $\% S S_{i}$ values. Although we do not have an analytical proof, this led us to believe that there is an approximate linear relation (as in a single stock point model) between the standard deviation of demand and performance measures of a retailer (such as $C_{i}\left(S_{1}, S_{2}\right) \approx \sigma_{i} \times$ constant and safety stock ${ }_{i} \approx$ $\sigma_{i} \times$ constant).

(4) Total cost improvement, \%TC or improvement for a retailer, $\% C_{i}$, also depend on the retailer lead time parameters. As retailer lead times increase, $\% T C$ decreases. This effect is expected, as in the cases of higher retailer lead times the relative length of risk-pooling period, $L$, over the length of the cycle decreases. These are observed both in Tables 2-4. Notice that in Table 3, both $\% S S_{1}$ and \%SS decrease as we move from $\left(l_{1}, l_{2}\right)=(1,1)$ to $\left(l_{1}, l_{2}\right)=(1,3)$ and $\left(l_{1}, l_{2}\right)=(3,3)$. A similar observation holds in Table 4 for $\% T C$ and $\% C_{1}$. Obviously, the supplier lead time, $L$, also has an effect on the performance of our policy. In our experiments, supplier lead time is fixed as $L=5$. We also computed cases where $L=7$, and observed that the performance of our model improves, as expected.

(5) We observe a decrease in \%TC and \%SS as unit backorder cost increases (see, for example, Table 2).
Table 5 Transfer of Stock Probabilities

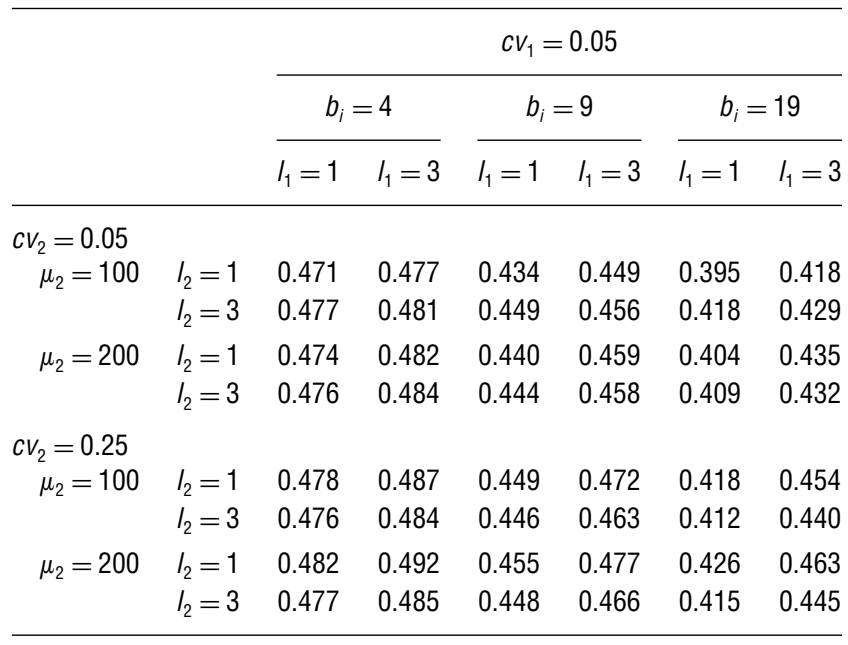

Although there is no clear intuition as to why this phenomena is observed, in what follows, we provide a plausible explanation.

One can check from Table 1 that as $b$ increases, the increase in $Z_{i}$ is smaller than the increase in $S_{i}^{*}$. Therefore, as $b$ increases, the gap between $S_{i}^{*}$ and $Z_{i}$ (which was defined as $\Delta_{i}$ in Equation (3)) increases. One can also check that in all the cases in Table $1 \Delta_{i}>500$, and hence $F_{1}^{(L)}\left(\Delta_{1}\right)>0.5$ (since $\mu_{1}=\mu_{2}=100$ and $L=5$ ). Hence, for the parameter sets presented, it becomes more likely for the retailers to end up above their respective $Z_{i}$ values at the end of supplier lead time, and occurrence of transfer of stock becomes less likely. Because retailers do not use the advantage of stock transfer (as frequently as before), the improvement of our model deteriorates.

This phenomena can be observed in Table 5, where we present $P\left(\Delta_{1}, \Delta_{2}\right)$ values for the parameter sets used in our computations. For the parameter sets that we used, $P\left(\Delta_{1}, \Delta_{2}\right)$ values range from 0.395 to 0.492 . It can be observed that as $b$ increases (for both retailers), $P\left(\Delta_{1}, \Delta_{2}\right)$ decreases.

Of course, these observations would have been different if $\Delta_{i}^{\prime}$ s (and hence $F_{i}^{(L)}\left(\Delta_{i}\right)^{\prime} \mathrm{s}$ ) were located differently. Therefore we conclude that the behavior of our model's performance with respect to a change in $b$ depends on the location of corresponding $\Delta_{i}$ values.

\subsection{Comparison with the Centralized Model}

Obviously, the total expected cost incurred by retailers would attain its minimum when the system operates 
in a centralized manner. That is, instead of retailers individually determining their order-up-to levels $S_{1}^{*}$ and $S_{2}^{*}$, a systemwide order-up-to level $S_{c e n}$ is determined. Then, at the end of the supplier lead time, a decision is made on how much stock to allocate for each retailer. To understand how close our policy gets (in terms of systemwide expected cost) to the centralized model, we devised an experiment to compare the performance of our model against the performance of the centralized supply chain. We only considered cases where $\sigma_{1}=\sigma_{2}$ and $l_{1}=l_{2}$. Essentially, for the centralized model, this corresponds to the two-echelon model of Eppen and Schrage (1981). In Table 1, we present systemwide expected cost for the centralized model in the column $T C^{c e n}$, and the systemwide order-up-to level in the column $S_{c e n}$. We define $\% D$ as the percent deviation (in terms of systemwide cost) of the policy that we propose from the centralized model

$$
\% D=\frac{\sum_{i} C_{i}\left(S_{1}^{*}, S_{2}^{*}\right)-T C^{c e n}}{T C^{c e n}} \times 100 .
$$

We report $\% D$ figures in Table 2 . It can be observed that for the cases that we considered, the deviation of the total cost of our model from the centralized solution is no more than $7.8 \%$. This deviation decreases as $l_{i}$ increases, and increases as $b$ increases, as one would expect. In Table 2, we present the percent deviation of the proposed model from the centralized model in terms of total safety stocks in the column $\% S S_{c e n}$ (generally being around 5\%), which exhibits a similar behavior

$$
\% S S_{c e n}=\frac{\sum_{i} S_{i}^{*}-S_{c e n}}{S_{c e n}-\sum_{i}\left(L+l_{i}+1\right) \mu_{i}} \times 100 .
$$

Both the proposed model and the centralized model take advantage of correcting shortfall and excess stock situations that occur during the supplier lead time. Therefore, as the weight of the supplier lead time in the overall cycle time decreases, their performance get close to each other. On the other hand, the centralized model gets even better as the backorder cost increases. We should keep in mind that the centralized model has the advantage of delaying any allocation of stock during the supplier lead time, whereas in the proposed model, each retailer determines its order-up-to level at the beginning of the order cycle. Moreover, in the centralized model, an allocation that favors one of the retailers, but deteriorates the other can be performed, as it tries to minimize systemwide costs. In the proposed model, on the other hand, a possible backorder occurrence will be avoided through a transfer of stock only if the transfer improves the performances of both.

We define $\% B$ as the percent benefits of centralization (over the decentralized model without stock transfer) that would be captured by employing the policy we propose

$$
\% B=\frac{\sum_{i} C_{i}^{i n d}-\sum_{i} C_{i}\left(S_{1}^{*}, S_{2}^{*}\right)}{\sum_{i} C_{i}^{i n d}-T C^{c e n}} .
$$

The last column of Table 2 illustrates that approximately $70 \%$ of the benefits of the centralized model over the decentralized model can be obtained by employing our model. Therefore, a decentralized model operating under the prescribed optimal orderup-to levels and the transfer policy proposed can explain almost $70 \%$ of the improvement that would have been obtained by a centralized model.

\subsection{Understanding the Source of Improvement}

The policy that we propose has two major sources that lead to improvement over the decentralized model. The first source of improvement is the possibility of stock transfer. The second source, on the other hand, is the utilization of the other retailer's inventory decision in making a decision on one's order-up-to level: the Nash equilibrium. Therefore, in principle, we can divide the total improvement $C_{i}^{\text {ind }}-$ $C_{i}\left(S_{1}^{*}, S_{2}^{*}\right)$ into two parts. Although we do not have exact means for differentiating these two sources, we utilized the following approach to come up with approximate measures of them. If retailers obtain their order-up-to levels by using Equation (11), but do experience transfer of stock at the end of supplier lead time, their expected cost will be $C_{i}\left(S_{1}^{\text {ind }}, S_{2}^{\text {ind }}\right)$, $i=1,2$. Therefore, an approximate measure for the improvement because of the transfer of stock, $P O L_{i}$, is given as

$$
P O L_{i}=C_{i}^{\text {ind }}-C_{i}\left(S_{1}^{\text {ind }}, S_{2}^{\text {ind }}\right) .
$$

We define $\% P O L_{i}$ as the percent improvement because of transfer of stock

$$
\% P O L_{i}=\frac{C_{i}^{\text {ind }}-C_{i}\left(S_{1}^{\text {ind }}, S_{2}^{\text {ind }}\right)}{C_{i}^{\text {ind }}-C_{i}\left(S_{1}^{*}, S_{2}^{*}\right)} \times 100 .
$$




\begin{tabular}{crrrr} 
Table 6 & \multicolumn{3}{c}{$\begin{array}{l}\text { Percent Cost Improvement for Retailer } 1 \\
\text { Because of Transfer of Stock }\end{array}$} \\
\hline \multicolumn{5}{c}{$\left(I_{1}, I_{2}\right)$} \\
\cline { 2 - 5 }$\% P O L_{1}$ & $(1,1)$ & $(1,3)$ & $(3,1)$ & $(3,3)$ \\
\hline$\left(\sigma_{1}, \sigma_{2}\right)$ & & & & \\
$(5,10)$ & 75.7 & 81.9 & 76.5 & 82.9 \\
$(5,50)$ & 71.9 & 79.8 & 72.6 & 80.4 \\
$(25,10)$ & 100.0 & 99.8 & 99.0 & 92.5 \\
$(25,50)$ & 75.7 & 81.9 & 76.6 & 100.0 \\
\hline
\end{tabular}

We present $C_{i}\left(S_{1}^{\text {ind }}, S_{2}^{\text {ind }}\right)$ values in Table 1 and $\% P O L_{1}=\% P O L_{2}=\% P O L$ values in Table 2 for identical retailers. One can observe that $\% P O L$ decreases as the unit backorder cost increases. The explanation of the behavior of $\% P O L$, as $b$ changes, parallels our explanation of \%TC (Item 5 of $\S 6.1$ ): transfer of stock becomes less likely. On the other hand, $\% P O L$ decreases as the retailer lead time increases. As noted in Item 4 of $\S 6.1$, percent improvement of the proposed policy decreases as $l_{i}$ increases, because of the decreasing weight of the risk-pooling period $(L)$ over the order cycle. We infer that in such cases, determining the precise order-up-to level quantities become less important. Therefore most of the (already diminished) improvement stems from the stock transfer.

In Table 6, we present $\% P O L_{1}$ values for the case $\mu_{1}=100, \mu_{2}=200, b_{1}=b_{2}=19$. As can be seen from Table $6,\left(1-\% P O L_{1}\right)$ values (approximately the percentage of improvement that comes from the equilibrium solution) are in the range of $15 \%-20 \%$ for most of the cases.

\section{Summary of Managerial Implications and Conclusions}

In this paper, we considered a decentralized supply chain of two independent retailers (or manufacturers) and a supplier. In the system that we analyzed, retailers order a common product (or raw material) from the supplier to fulfill their own random customer demand. The supplier has ample capacity to satisfy the orders placed by the retailers, but there is a fixed lead time (supplier lead time) associated with order preparation (because of supplier's manufacturing or ordering lead time, packaging, and loading times at the supplier's plant). At the end of the supplier lead time, orders are shipped to retailers. Before retailer orders are shipped, they are given an opportunity to readjust their orders (by transferring part of an order quantity from one retailer to the other), as long as this transaction improves expected costs of both retailers. Moreover, retailers share relevant information (such as costs, demand distributions, inventory levels) to be able to make a better informed decision on order-up-to levels. Under this setting, we derived unique equilibrium order-up-to levels for the retailers. The derivation is based on a single-cycle analysis, but can be generalized under some mild conditions, as given in $\S 3.3$.

Our computational results gave us important managerial insights on design and operation of such systems, some of which are summarized as follows:

(1) The model that we propose may lead to considerable benefits in terms of expected costs and safety stocks. Total safety stock improvement can be as high as $16 \%$, whereas total cost improvement can be as much as $14 \%$.

(2) The benefits are much higher for the retailer with relatively smaller standard deviation of demand (percent improvement in the safety stock may be as high as $33 \%$; percent improvement in cost may be as much as $22 \%$ ). Moreover, the retailer with the smaller standard deviation increases its percent improvement as the other retailer's standard deviation gets higher.

(3) Benefits of the proposed model increase whenever the supplier lead time is long and the retailer lead time is short.

(4) Combining the last two observations, a retailer with reasonably low demand variation, having fast transportation capability of shipping goods from the cross-docking warehouse would be willing to participate in transfer of stock and information sharing.

(5) Expected total cost of the proposed model does not show a considerable deviation from the centralized model.

(6) Approximately $70 \%$ of the expected cost benefits of a centralized model can be gained from the model that we propose. By applying the proposed policy, a system can achieve a considerable percent of the performance of a centralized model without sacrificing the individual performance of a retailer. 
(7) Around $80 \%$ of the cost improvement is because of the transfer of stock at the cross-docking warehouse and the remaining $20 \%$ is attributed to the Nash equilibrium. This is encouraging, as information sharing may be more difficult then implementing the transfer policy at the cross-docking warehouse.

Our work can be extended in several directions. One possible extension is to consider more than two; say, $N$ retailers. The main difficulty is in defining a policy for the transfer of stock at the cross-docking warehouse. A simple transfer rule is to index retailers in a cyclic order in such a way that whenever retailer $i$ has an excess, it is used to satisfy the shortage of retailer $i+1(\bmod N)$. In fact, under such welldefined transfer rules, one can derive the distribution of net change in the stock position, $H_{i}(x)$, much like the derivation in $\S 4$.

Another potential extension is to consider fixed retailer shipment and transfer costs. The form of the optimal order-up-to levels under fixed costs associated with supplier-to-retailer shipments and fixed transfer costs is worthwhile to investigate. In our analysis, we assumed an uncapacitated supplier. Apparently, if the supply is limited, a rationing game at the supplier, on top of the transfer game that we considered should also be incorporated.

\section{Acknowledgments}

The authors thank the senior editor and the anonymous referee for suggesting several important changes and modifications that led to considerable improvement of this paper. Refik Güllü and Nesim Erkip were at Middle East Technical University when this research was carried out. Nesim Erkip was at Eindhoven University of Technology when parts of the revision were carried out.

\section{Appendix}

Proof of Proposition 1. It is sufficient to show that $C_{1}\left(Z_{1}, S_{2}\right)<C_{1}\left(Z_{1}-\delta, S_{2}\right)$ for any $\delta>0$. For $S_{1}=Z_{1}$, we have $A_{1}=0, B_{1}=D_{1}(L)$, and hence $\eta_{2}=0$ and $\eta_{1}=$ $\min \left\{D_{1}(L), A_{2}\right\}$. For $S_{1}=Z_{1}-\delta$, we have $A_{1}=0, B_{1}=$ $D_{1}(L)+\delta$, and therefore $\eta_{2}=0$ and $\eta_{1}=\min \left\{D_{1}(L)+\delta, A_{2}\right\}$. Then,

$$
\begin{gathered}
X_{1}=D_{1}(L)-\min \left\{D_{1}(L), A_{2}\right\}, \\
X_{1}^{\delta}=D_{1}(L)-\min \left\{D_{1}(L)+\delta, A_{2}\right\},
\end{gathered}
$$

where $X_{1}^{\delta}$ is the net change variable corresponding to $S_{1}=$ $Z_{1}-\delta$. It can easily be verified that $0 \leq X_{1} \leq \delta+X_{1}^{\delta}$ for every point in the sample space generating $\left(D_{1}(L), D_{2}(L)\right)$. Since $Z_{1}$ is the minimizer of $G_{1}(z)$, and $G_{1}(z)$ is convex,

$$
G_{1}\left(Z_{1}-X_{1}\right) \leq G_{1}\left(Z_{1}-\delta-X_{1}^{\delta}\right),
$$

and hence, as there is at least one element in the sample space with the above holding as strict inequality, $C_{1}\left(Z_{1}, S_{2}\right)<C_{1}\left(Z_{1}-\delta, S_{2}\right)$.

Proof of Lemma 1 for $L \geq 2$. Consider Equations (6)-(9). Suppose that $\eta_{1, t}>0$, and hence $\eta_{2, t}=0$. To compensate the transfer of stock, retailers modify $O_{1, t-L+1, t-1}$ and $\mathrm{O}_{2, t-L+1, t-1}$ in the opposite direction. That is, $O_{1, t-L+1, t-1}$ is decreased by $\eta_{1, t}$, and $O_{2, t-L+1, t-1}$ is increased by $\eta_{1, t}$. Practically, the transfer of stock is equivalent to a temporary borrowing until the next orders arrive at the cross-docking warehouse. Note that the "complete" inventory positions remain the same under this rule of transfer of stock. Using the convention described above, the orders placed in period $t-L+1$ are modified as

$$
\begin{aligned}
& O_{1, t-L+1, t}=O_{1, t-L+1, t-1}-\eta_{1, t}+\eta_{2, t}, \\
& O_{2, t-L+1, t}=O_{2, t-L+1, t-1}-\eta_{2, t}+\eta_{1, t},
\end{aligned}
$$

with other orders in the state vector being unaffected:

$$
O_{i, s, t}=O_{i, s, t-1}, \quad i=1,2, s=t-L+2, \ldots, t-1 .
$$

Note that Equation (A.3) vanishes for $L=2$. Equations (A.1)-(A.2) are valid under the assumption that the orders $O_{1, t-L+1, t-1}$ and $O_{2, t-L+1, t-1}$ being present at the warehouse at that moment are large enough, and $O_{1, t-L, t-1}$ and $O_{2, t+L, t-1}$ are large enough. If $\eta_{1, t}>0$ (and thus $\left.\eta_{2, t}=0\right)$, then it is required that $\eta_{1, t} \leq O_{2, t-L, t-1}$ and $\eta_{1, t} \leq$ $O_{1, t-L+1, t-1}$. If $\eta_{2, t}>0$ (and thus $\eta_{1, t}=0$ ), then it is required that $\eta_{2, t} \leq O_{1, t-L, t-1}$ and $\eta_{2, t} \leq O_{2, t-L+1, t-1}$. This assumption is similar to the "sufficient stock" assumption given above. Note that in this case, the sufficient stock assumption ensures that there is enough stock (say, $O_{1, t-L+1, t-1}$ ) to raise inventory positions of retailers to predetermined levels (by transferring an amount of $\left.\eta_{1, t}\right)$.

By using (8), (9), (A.1), and (A.2), we obtain the following:

$$
\begin{aligned}
I_{i, t}^{\prime}+O_{i, t-L+1, t}=I_{i, t}+O_{i, t-L+1, t-1} & \\
& \quad i=1,2, t=0,1, \ldots .
\end{aligned}
$$

Combining (A.4) with (A.3) shows that the "complete" inventory position of retailer $i$ does not change under the transfer of stock

$$
\begin{array}{r}
I_{i, t}^{\prime}+\sum_{s=t-L+1}^{t-1} O_{i, s, t}=I_{i, t}+\sum_{s=t-L+1}^{t-1} O_{i, s, t-1,} \\
\quad i=1,2, t \geq 0 .
\end{array}
$$

Now, by (A.3), we find

$$
\begin{aligned}
O_{i, s, t}=O_{i, s, t-1}=\cdots & =O_{i, s, s} \\
& \quad i=1,2, t \geq 0, s=t-L+2, \ldots, t-1
\end{aligned}
$$


(with the convention that this equation vanishes if $L=2$, and $O_{i, s, t}=O_{i, s,-1}$ when $t \leq 2$ ). Hence, (A.5) may be rewritten as

$$
I_{i, t}^{\prime}+\sum_{s=t-L+1}^{t-1} O_{i, s, t}=I_{i, t}+\sum_{s=t-L+1}^{t-1} O_{i, s, s}, \quad i=1,2, t \geq 0 .
$$

Thus

$$
\begin{aligned}
O_{i, t, t} & =S_{i}-\left(I_{i, t}^{\prime}+\sum_{s=t-L+1}^{t-1} O_{i, s, t}\right) \\
& =S_{i}-\left(I_{i, t}+\sum_{s=t-L+1}^{t-1} O_{i, s, s}\right), \quad i=1,2, t \geq 0 .
\end{aligned}
$$

Further, by (A.4), for the "partial" inventory position we find

$$
\begin{aligned}
I_{i, t+1} & =I_{i, t}^{\prime}+O_{i, t-L+1, t}-D_{i, t} \\
& =I_{i, t}+O_{i, t-L+1, t-L+1}-D_{i, t}, \quad i=1,2, t \geq 0 .
\end{aligned}
$$

By using (A.8) and (A.7), for the "complete" inventory position we find

$$
\begin{aligned}
I_{i, t}+\sum_{s=t-L+1}^{t-1} O_{i, s, s} & =\left(I_{i, t-1}+O_{i, t-L, t-L}-D_{i, t-1}\right)+\sum_{s=t-L+1}^{t-1} O_{i, s, s} \\
& =\left(I_{i, t-1}+\sum_{s=t-L}^{t-1} O_{i, s, s}\right)-D_{i, t-1} \\
& =S_{i}-D_{i, t-1}, \quad i=1,2, t \geq 1 .
\end{aligned}
$$

Next, by substitution of (A.9) into (A.7), we obtain

$$
O_{i, t, t}=D_{i, t-1}, \quad i=1,2, t \geq 1 \text {. }
$$

Thus, under the specified rule of order modification, each retailer orders the previous period's demand (implying the usual stationary order-up-to level policy). Therefore, by using (A.7) and (A.9) for $i=1,2$ and $t \geq L$, we obtain

$$
I_{i, t}=S_{i}-\sum_{s=t-L}^{t-1} D_{i, s}=S_{i}-D_{i}(L) .
$$

Then, by (6), (7), and (A.10),

$$
\begin{aligned}
I_{i, t}-Z_{i} & =\left(S_{i}-Z_{i}\right)-D_{i}(L)=\Delta_{i}-D_{i}(L), \quad i=1,2, t \geq L, \\
\eta_{1, t} & =\min \left\{\left(\Delta_{2}-D_{2}(L)\right)^{+},\left(D_{1}(L)-\Delta_{1}\right)^{+}\right\}, \quad t \geq L, \\
\eta_{2, t} & =\min \left\{\left(\Delta_{1}-D_{1}(L)\right)^{+},\left(D_{2}(L)-\Delta_{2}\right)^{+}\right\}, \quad t \geq L .
\end{aligned}
$$

By (8), (9), and (A.10), we find

$$
\begin{array}{ll}
I_{1, t}^{\prime}=I_{1, t}+\eta_{1, t}-\eta_{2, t}=S_{1}-\left(D_{1}(L)-\eta_{1, t}+\eta_{2, t}\right), & t \geq L, \\
I_{2, t}^{\prime}=I_{2, t}+\eta_{2, t}-\eta_{1, t}=S_{2}-\left(D_{2}(L)-\eta_{2, t}+\eta_{1, t}\right), \quad t \geq L,
\end{array}
$$

which is equivalent to $S_{i}-X_{i}(i=1,2)$ in (4) and (5).
Proof of Proposition 2. We condition $X_{1}$ on $D_{1}(L)$ :

$$
\begin{aligned}
\operatorname{Pr}\left\{X_{1} \leq x\right\}= & \operatorname{Pr}\left\{X_{1} \leq x, D_{1}(L) \leq \Delta_{1}\right\} \\
& +\operatorname{Pr}\left\{X_{1} \leq x, D_{1}(L)>\Delta_{1}\right\} .
\end{aligned}
$$

For the first probability term in (A.11),

$$
\begin{aligned}
\operatorname{Pr}\{ & \left.X_{1} \leq x, D_{1}(L) \leq \Delta_{1}\right\} \\
& =\int_{0}^{\Delta_{1}} \operatorname{Pr}\left\{X_{1} \leq x \mid D_{1}(L)=y\right\} f_{1}^{(L)}(y) d y \\
& =\int_{0}^{\Delta_{1}} \operatorname{Pr}\left\{y+\eta_{2} \leq x \mid D_{1}(L)=y\right\} f_{1}^{(L)}(y) d y \\
& =\int_{0}^{\Delta_{1}}\left[1-\operatorname{Pr}\left\{\eta_{2}>x-y \mid D_{1}(L)=y\right\}\right] f_{1}^{(L)}(y) d y \\
& =\int_{0}^{\Delta_{1}}\left[1-\operatorname{Pr}\left\{\min \left(\Delta_{1}-y, B_{2}\right)>x-y \mid D_{1}(L)=y\right\}\right] f_{1}^{(L)}(y) d y \\
& =\int_{0}^{\Delta_{1}}\left[1-\operatorname{Pr}\left\{B_{2}>x-y\right\} 1_{\left\{\Delta_{1}>x\right\}}\right] f_{1}^{(L)}(y) d y \\
& =\left\{\begin{array}{cc}
\int_{0}^{\Delta_{1}} \operatorname{Pr}\left\{B_{2} \leq x-y\right\} f_{1}^{(L)}(y) d y, & x<\Delta_{1} \\
F_{1}^{(L)}\left(\Delta_{1}\right) & x \geq \Delta_{1} .
\end{array}\right.
\end{aligned}
$$

The second and the fourth equalities are obtained by noting that $\eta_{1}=0$ and $A_{1}=\Delta_{1}-y$ on $D_{1}(L) \leq \Delta_{1}$. For the second probability term in (A.11),

$$
\begin{aligned}
\operatorname{Pr}\{ & \left.X_{1} \leq x, D_{1}(L)>\Delta_{1}\right\} \\
& =\int_{\Delta_{1}}^{\infty} \operatorname{Pr}\left\{X_{1} \leq x \mid D_{1}(L)=y\right\} f_{1}^{(L)}(y) d y \\
& =\int_{\Delta_{1}}^{\infty} \operatorname{Pr}\left\{y-\eta_{1} \leq x \mid D_{1}(L)=y\right\} f_{1}^{(L)}(y) d y \\
& =\int_{\Delta_{1}}^{\infty} \operatorname{Pr}\left\{\eta_{1} \geq y-x \mid D_{1}(L)=y\right\} f_{1}^{(L)}(y) d y \\
& =\int_{\Delta_{1}}^{\infty} \operatorname{Pr}\left\{\min \left(y-\Delta_{1}, A_{2}\right) \geq y-x \mid D_{1}(L)=y\right\} f_{1}^{(L)}(y) d y \\
& =\int_{\Delta_{1}}^{\infty} \operatorname{Pr}\left\{A_{2}>y-x\right\} 1_{\left\{\Delta_{1} \leq x\right\}} f_{1}^{(L)}(y) d y \\
& = \begin{cases}0 & x<\Delta_{1}, \\
\int_{\Delta_{1}}^{\infty} \operatorname{Pr}\left\{A_{2} \geq y-x\right\} f_{1}^{(L)}(y) d y & x \geq \Delta_{1} .\end{cases}
\end{aligned}
$$

The second and fourth equalities are obtained by noting that $\eta_{1}=0$ and $B_{1}=y-\Delta_{1}$ on $D_{1}(L)>\Delta_{1}$. Combining two probability terms yields

$$
\operatorname{Pr}\left\{X_{1} \leq x\right\}= \begin{cases}\int_{0}^{\Delta_{1}} \operatorname{Pr}\left\{B_{2} \leq x-y\right\} f_{1}^{(L)}(y) d y & x<\Delta_{1}, \\ F_{1}^{(L)}\left(\Delta_{1}\right)+\int_{\Delta_{1}}^{\infty} \operatorname{Pr}\left\{A_{2} \geq y-x\right\} f_{1}^{(L)}(y) d y & x \geq \Delta_{1} .\end{cases}
$$


We can obtain the probability distributions for $A_{2}$ and $B_{2}$ as

$$
\begin{gathered}
\operatorname{Pr}\left\{A_{2} \geq y-x\right\}= \begin{cases}1 & y<x, \\
F_{2}^{(L)}\left(\Delta_{2}+x-y\right) & x \leq y<\Delta_{2}, \\
0 & y \geq x+\Delta_{2} .\end{cases} \\
\operatorname{Pr}\left\{B_{2} \leq x-y\right\}= \begin{cases}0 & x<y, \\
F_{2}^{(L)}\left(\Delta_{2}+x-y\right) & x \geq y .\end{cases}
\end{gathered}
$$

By inserting Equations (A.13) and (A.14) in Equation (A.12) and simple algebraic manipulation, we obtain Proposition 2.

Proof of Theorem 1. For part (i), we prove the continuity of $C_{1}\left(S_{1}, S_{2}\right)$. The case for $i=2$ is the same. In Proposition 1 , we showed that $S_{1}^{*} \geq Z_{1}$. On the other hand, since $\eta_{1} \geq 0$ and $\eta_{2}=\min \left\{A_{1}, B_{2}\right\} \leq D_{2}(L)$,

$$
\begin{aligned}
X_{1} & =D_{1}(L)-\eta_{1}+\eta_{2} \\
& \leq D_{1}(L)+D_{2}(L) .
\end{aligned}
$$

Therefore $S_{1}^{*} \leq \widetilde{S}_{1}$, where $\widetilde{S}_{1}$ is obtained as

$$
F_{2}^{(L)} * F_{1}^{\left(L+l_{1}+1\right)}\left(\tilde{S}_{1}\right)=\frac{b_{1}}{b_{1}+h_{1}} .
$$

Similarly, $S_{2}^{*} \leq \widetilde{S}_{2}$, where $\widetilde{S}_{2}$ is given by

$$
F_{1}^{(L)} * F_{2}^{\left(L+l_{2}+1\right)}\left(\widetilde{S}_{2}\right)=\frac{b_{2}}{b_{2}+h_{2}} .
$$

Therefore $\left(S_{1}, S_{2}\right) \in \Omega=\left[Z_{1}, \tilde{S}_{1}\right] \times\left[Z_{2}, \widetilde{S}_{2}\right]$, a compact subset of $R^{2}$. Let $\left(S_{1}^{k}, S_{2}^{k}\right)$ be a sequence in $S$ converging to $\left(S_{1}, S_{2}\right)$ (define all relevant random variables $X_{i}^{k}, A_{i}^{k}, B_{i}^{k}$ associated with $\left.S_{i}^{k}\right)$. We can write $C_{1}\left(S_{1}^{k}, S_{2}^{k}\right)$ as

$$
\begin{aligned}
C_{1}\left(S_{1}^{k}, S_{2}^{k}\right)= & \left(h_{1}+b_{1}\right) E\left[\left(S_{1}^{k}-X_{1}^{k}-D_{1}\left(l_{1}+1\right)\right)^{+}\right] \\
& +b_{1} E\left[X_{1}^{k}+D_{1}\left(l_{1}+1\right)-S_{1}^{k}\right] .
\end{aligned}
$$

We first note that $\left(S_{1}^{k}-X_{1}^{k}-D_{1}\left(l_{1}+1\right)\right)^{+} \leq \widetilde{S}_{1}$, and $S_{1}^{k}$ and $X_{1}^{k}$ converge to $S_{1}$ and $X_{1}$, respectively. Therefore the first expectation in (A.15) converges to $E\left[\left(S_{1}-X_{1}-D_{1}\right.\right.$. $\left.\left.\left(l_{1}+1\right)\right)^{+}\right]$by bounded convergence theorem (Billingsley 1986). Since $X_{1}^{k} \leq D_{1}(L)+D_{2}(L)$, the second expectation in (A.15) converges to $E\left[X_{1}+D_{1}\left(l_{1}+1\right)-S_{1}\right]$ by dominated convergence theorem (Billingsley 1986). Therefore $C_{1}\left(S_{1}^{k}, S_{2}^{k}\right)$ converges to $C_{1}\left(S_{1}, S_{2}\right)$, which proves continuity.

For part (ii), we show the convexity of $C_{1}\left(S_{1}, S_{2}\right)$ for a given $S_{2}$; the argument for $C_{2}\left(S_{1}, S_{2}\right)$ is basically the same by symmetry. Recall that $S_{1}-X_{1}=S_{1}-D_{1}(L)+\eta_{1}-\eta_{2}$. For a given $S_{2}$ and $D_{2}(L)$, we either have $A_{2}>0$ (and $B_{2}=0$ ) or $A_{2}=0$ (and $\left.B_{2}>0\right)$. Hence

$$
\begin{aligned}
C_{1}\left(S_{1}, S_{2}\right)= & E\left[G_{1}\left(S_{1}-X_{1}\right)\right]=E\left[G_{1}\left(S_{1}-X_{1}\right) 1_{\left\{A_{2}>0\right\}}\right] \\
& +E\left[G_{1}\left(S_{1}-X_{1}\right) 1_{\left\{A_{2}=0\right\}}\right] .
\end{aligned}
$$

Case 1. $A_{2}>0$

On $A_{2}>0$, we can write $S_{1}-X_{1}$ as

$$
S_{1}-X_{1}= \begin{cases}S_{1}-D_{1}(L) & D_{1}(L)<S_{1}-Z_{1}, \\ Z_{1} & S_{1}-Z_{1} \leq D_{1}(L) \leq S_{1}-Z_{1}+A_{2}, \\ S_{1}-D_{1}(L)+A_{2} & D_{1}(L) \geq S_{1}-Z_{1}+A_{2} .\end{cases}
$$

Therefore, on $A_{2}>0, C_{1}\left(S_{1}, S_{2}\right)$ becomes

$$
\begin{aligned}
& E\left[G_{1}\left(S_{1}-X_{1}\right) 1_{\left\{A_{2}>0\right\}}\right] \\
& =\int_{\left\{y: A_{2}>0\right\}}\left\{\int_{0}^{S_{1}-Z_{1}} G_{1}\left(S_{1}-w\right) f_{1}^{(L)}(w) d w\right. \\
& \quad+\int_{S_{1}-Z_{1}}^{S_{1}-Z_{1}+A_{2}} G_{1}\left(Z_{1}\right) f_{1}^{(L)}(w) d w \\
& \left.\quad+\int_{S_{1}-Z_{1}+A_{2}}^{\infty} G_{1}\left(S_{1}-w+A_{2}\right) f_{1}^{(L)}(w) d w\right\} f_{2}^{(L)}(y) d y .
\end{aligned}
$$

The second derivative of (A.18) with respect to $S_{1}$ is

$$
\begin{aligned}
& E\left[G_{1}^{\prime \prime}\left(S_{1}-X_{1}\right) 1_{\left\{A_{2}>0\right\}}\right] \\
& =\int_{\left\{y: A_{2}>0\right\}}\left\{\int_{0}^{S_{1}-Z_{1}} G_{1}^{\prime \prime}\left(S_{1}-w\right) f_{1}^{(L)}(w) d w\right. \\
& \left.\quad+\int_{S_{1}-Z_{1}+A_{2}}^{\infty} G_{1}^{\prime \prime}\left(S_{1}-w+A_{2}\right) f_{1}^{(L)}(w) d w\right\} f_{2}^{(L)}(y) d y>0 .
\end{aligned}
$$

Because $Z_{1}$ is the unique minimizer of $G_{1}(x)$, both $G_{1}^{\prime \prime}$ terms in (A.19) are strictly positive.

Case 2. $A_{2}=0$

On $A_{2}=0$, we can write $S_{1}-X_{1}$ as

$$
S_{1}-X_{1}= \begin{cases}S_{1}-D_{1}(L)-B_{2} & D_{1}(L)<S_{1}-Z_{1}-B_{2}, \\ Z_{1} & S_{1}-Z_{1}-B_{2} \leq D_{1}(L) \leq S_{1}-Z_{1}, \\ S_{1}-D_{1}(L) & D_{1}(L) \geq S_{1}-Z_{1} .\end{cases}
$$

Therefore, on $A_{2}=0, C_{1}\left(S_{1}, S_{2}\right)$ becomes

$$
\begin{aligned}
& E\left[G_{1}\left(S_{1}-X_{1}\right) 1_{\left\{A_{2}=0\right\}}\right] \\
& \begin{aligned}
\int_{\left\{y: A_{2}=0\right\}} & \left\{\int_{0}^{S_{1}-Z_{1}-B_{2}} G_{1}\left(S_{1}-w-B_{2}\right) f_{1}^{(L)}(w) d w\right. \\
& +\int_{S_{1}-Z_{1}-B_{2}}^{S_{1}-Z_{1}} G_{1}\left(Z_{1}\right) f_{1}^{(L)}(w) d w \\
& \left.+\int_{S_{1}-Z_{1}}^{\infty} G_{1}\left(S_{1}-w\right) f_{1}^{(L)}(w) d w\right\} f_{2}^{(L)}(y) d y .
\end{aligned}
\end{aligned}
$$

The second derivative of (A.21) with respect to $S_{1}$ is

$$
\begin{aligned}
& E\left[G_{1}^{\prime \prime}\left(S_{1}-X_{1}\right) 1_{\left\{A_{2}=0\right\}}\right] \\
& =\int_{\left\{y: A_{2}=0\right\}}\left\{\int_{0}^{S_{1}-Z_{1}-B_{2}} G_{1}^{\prime \prime}\left(S_{1}-w-B_{2}\right) f_{1}^{(L)}(w) d w\right. \\
& \left.+\int_{S_{1}-Z_{1}}^{\infty} G_{1}^{\prime \prime}\left(S_{1}-w\right) f_{1}^{(L)}(w) d w\right\} f_{2}^{(L)}(y) d y>0 .
\end{aligned}
$$


Again, as $Z_{1}$ is the unique minimizer of $G_{1}(x)$, both $G_{1}^{\prime \prime}$ terms in (A.22) are strictly positive.

We prove part (iii) for $i=1$ (the case $i=2$ is the same by symmetry). Equation (5) can be written as

$$
\begin{aligned}
C_{1}\left(S_{1}, S_{2}\right)= & \int_{0}^{\Delta_{1}} G_{1}\left(S_{1}-w\right) r_{11}(w) d w \\
& +\int_{\Delta_{1}}^{\infty} G_{1}\left(S_{1}-w\right) r_{12}(w) d w+G\left(S_{1}-\Delta_{1}\right) P_{1}\left(\Delta_{1}\right) .
\end{aligned}
$$

Then, $U_{1}\left(S_{1}, S_{2}\right)$ becomes

$$
\begin{aligned}
U_{1}\left(S_{1}, S_{2}\right) \\
=\frac{\partial C_{1}\left(S_{1}, S_{2}\right)}{\partial S_{1}} \\
=\frac{\partial}{\partial S_{1}}\left\{\int_{0}^{\Delta_{1}} G_{1}\left(S_{1}-w\right) r_{11}(w) d w\right. \\
\left.\quad \quad \quad \int_{\Delta_{1}}^{\infty} G_{1}\left(S_{1}-w\right) r_{12}(w) d w+G_{1}\left(S_{1}-\Delta_{1}\right) P_{1}\left(\Delta_{1}\right)\right\} \\
=G_{1}\left(S_{1}-\Delta_{1}\right)\left\{r_{11}\left(\Delta_{1}\right)-r_{12}\left(\Delta_{1}\right)\right\}+G_{1}\left(Z_{1}\right) P_{1}^{\prime}\left(\Delta_{1}\right) \\
\quad+\int_{0}^{\Delta_{1}} G_{1}^{\prime}\left(S_{1}-w\right) r_{11}(w) d w+\int_{\Delta_{1}}^{\infty} G_{1}^{\prime}\left(S_{1}-w\right) r_{12}(w) d w .
\end{aligned}
$$

Noting that

$$
P_{1}^{\prime}\left(\Delta_{1}\right)=r_{12}\left(\Delta_{1}\right)-r_{11}\left(\Delta_{1}\right),
$$

and $S_{1}-\Delta_{1}=Z_{1}, U_{1}\left(S_{1}, S_{2}\right)$ simplifies to

$$
\begin{aligned}
U_{1}\left(S_{1}, S_{2}\right)= & \int_{0}^{\Delta_{1}} G_{1}^{\prime}\left(S_{1}-w\right) r_{11}(w) d w \\
& +\int_{\Delta_{1}}^{\infty} G_{1}^{\prime}\left(S_{1}-w\right) r_{12}(w) d w .
\end{aligned}
$$

By Equations (1) and (2), we also know that $G_{1}^{\prime}\left(Z_{1}\right)=0$. Hence

$$
\begin{aligned}
U_{1}\left(S_{1}, S_{2}\right)= & \int_{0}^{\Delta_{1}} G_{1}^{\prime}\left(S_{1}-w\right) r_{11}(w) d w \\
& +\int_{\Delta_{1}}^{\infty} G_{1}^{\prime}\left(S_{1}-w\right) r_{12}(w) d w+G^{\prime}\left(Z_{1}\right) P_{1}\left(\Delta_{1}\right) \\
= & \int_{0}^{\infty} G_{1}^{\prime}\left(S_{1}-w\right) d H_{1}(w) .
\end{aligned}
$$

Finally, we can rewrite (A.24) by using $G_{1}^{\prime}(x)=-b_{1}+$ $\left(h_{1}+b_{1}\right) F_{1}^{\left(l_{1}+1\right)}(x)$ for $x \geq 0$, and $G_{1}^{\prime}(x)=0$ for $x<0$ :

$$
\begin{aligned}
U_{1}\left(S_{1}, S_{2}\right) & =-b_{1}+\left(h_{1}+b_{1}\right) \int_{0}^{S_{1}} F_{1}^{\left(l_{1}+1\right)}\left(S_{1}-w\right) d H_{1}(w) \\
& =-b_{1}+\left(h_{1}+b_{1}\right) H_{1} * F_{1}^{\left(l_{1}+1\right)}\left(S_{1}\right) \\
& =-b_{1}+\left(h_{1}+b_{1}\right) \int_{0}^{S_{1}} H_{1}\left(S_{1}-w\right) f_{1}^{\left(l_{1}+1\right)}(w) d w .
\end{aligned}
$$

Therefore, for a given value of $S_{2}$, one can obtain the optimal order-up-to level of the second retailer, $S_{1}^{*}\left(S_{2}\right)$ by solving (A.25).
Proof of Theorem 2. We first show that $U_{1}\left(S_{1}, S_{2}\right)=0$ and $U_{2}\left(S_{1}, S_{2}\right)=0$ form decreasing curves in $\left(S_{1}, S_{2}\right)$ plane, and the slope of the curve

$$
J_{1}\left(S_{1}\right)=\left\{S_{2}: U_{1}\left(S_{1}, S_{2}\right)=0\right\}, \quad S_{1} \geq Z_{1}
$$

is less than the slope of the curve

$$
J_{2}\left(S_{1}\right)=\left\{S_{2}: U_{2}\left(S_{1}, S_{2}\right)=0\right\}, \quad S_{1} \geq 0,
$$

which establishes the uniqueness of the Nash equilibrium. In particular, we show that

(i) $U_{1}\left(S_{1}, S_{2}\right)=0$ and $U_{2}\left(S_{1}, S_{2}\right)=0$ form strictly decreasing curves in $\left(S_{1}, S_{2}\right)$ plane. That is,

$$
d J_{1}\left(S_{1}\right) / d S_{1}<0 \text { and } d J_{2}\left(S_{1}\right) / d S_{1}<0 .
$$

(ii) $d J_{1}\left(S_{1}\right) / d S_{1}<d J_{2}\left(S_{1}\right) / d S_{1}$.

Let $S_{2}^{1}$ and $S_{2}^{2}$ be values of $S_{2}$ solving $U_{1}\left(S_{1}, S_{2}\right)=0$ and $U_{2}\left(S_{1}, S_{2}\right)=0$ for a given value of $S_{1}$, respectively. Let $\partial S_{2}^{1} / \partial S_{1}$ and $\partial S_{2}^{2} / \partial S_{1}$ be derivatives of $U_{1}\left(S_{1}, S_{2}\right)=0$ and $U_{2}\left(S_{1}, S_{2}\right)=0$ at $\left(S_{1}, S_{2}\right)$. We use implicit differentiation of $U_{1}\left(S_{1}, S_{2}\right)=0$ with respect to $S_{1}$ to obtain

$$
\left(h_{1}+b_{1}\right) a_{1}\left(S_{1}, S_{2}\right)+\left(h_{1}+b_{1}\right)\left(1+\frac{\partial S_{2}^{1}}{\partial S_{1}}\right) d_{1}\left(S_{1}, S_{2}\right)=0,
$$

where

$$
\begin{aligned}
& a_{1}\left(S_{1}, S_{2}\right)=\left(1-F_{2}^{(L)}\left(\Delta_{2}\right)\right) \int_{0}^{Z_{1}} f_{1}^{(L)}\left(S_{1}-x\right) f_{1}^{\left(l_{1}+1\right)}(x) d x \\
& \quad+F_{2}^{(L)} \int_{Z_{1}}^{S_{1}} f_{1}^{(L)}\left(S_{1}-x\right) f_{1}^{\left(l_{1}+1\right)}(x) d x>0 \\
& \left(S_{1}, S_{2}\right) \\
& =\int_{0}^{Z_{1}} \int_{S_{1}-x}^{S_{1}-x+\Delta_{2}} f_{1}^{(L)}(y) f_{2}^{(L)}\left(\Delta_{2}-y+S_{1}-x\right) f_{1}^{\left(l_{1}+1\right)}(x) d x d y \\
& \quad+\int_{Z_{1}}^{S_{1}} \int_{0}^{S_{1}-x} f_{1}^{(L)}(y) f_{2}^{(L)}\left(\Delta_{2}-y+S_{1}-x\right) f_{1}^{\left(l_{1}+1\right)}(x) d x d y>0 .
\end{aligned}
$$$$
d_{1}\left(S_{1}, S_{2}\right)
$$

Therefore

$$
\frac{\partial S_{2}^{1}}{\partial S_{1}}=\frac{-\left\{a_{1}\left(S_{1}, S_{2}\right)+d_{1}\left(S_{1}, S_{2}\right)\right\}}{d_{1}\left(S_{1}, S_{2}\right)}<0 .
$$

Similarly, we use implicit differentiation of $U_{2}\left(S_{1}, S_{2}\right)=0$ with respect to $S_{1}$ and find

$$
\left(h_{2}+b_{2}\right) \frac{\partial S_{2}^{2}}{\partial S_{1}} a_{2}\left(S_{1}, S_{2}\right)+\left(h_{2}+b_{2}\right)\left(1+\frac{\partial S_{2}^{2}}{\partial S_{1}}\right) d_{2}\left(S_{1}, S_{2}\right)=0,
$$

where

$$
\begin{aligned}
a_{2}\left(S_{1}, S_{2}\right)= & \left(1-F_{1}^{(L)}\left(\Delta_{1}\right)\right) \int_{0}^{Z_{2}} f_{2}^{(L)}\left(S_{2}-x\right) f_{2}^{\left(l_{2}+1\right)}(x) d x \\
& +F_{1}^{(L)} \int_{Z_{2}}^{S_{2}} f_{2}^{(L)}\left(S_{2}-x\right) f_{2}^{\left(l_{2}+1\right)}(x) d x>0,
\end{aligned}
$$

$d_{2}\left(S_{1}, S_{2}\right)$

$$
\begin{aligned}
= & \int_{0}^{Z_{2}} \int_{S_{2}-x}^{S_{2}-x+\Delta_{1}} f_{2}^{(L)}(y) f_{1}^{(L)}\left(\Delta_{1}-y+S_{2}-x\right) f_{2}^{\left(l_{2}+1\right)}(x) d x d y \\
& +\int_{Z_{2}}^{S_{2}} \int_{0}^{S_{2}-x} f_{2}^{(L)}(y) f_{1}^{(L)}\left(\Delta_{1}-y+S_{2}-x\right) f_{2}^{\left(l_{2}+1\right)}(x) d x d y>0 .
\end{aligned}
$$


Then,

$$
\frac{\partial S_{2}^{2}}{\partial S_{1}}=\frac{-d_{2}\left(S_{1}, S_{2}\right)}{a_{2}\left(S_{1}, S_{2}\right)+d_{2}\left(S_{1}, S_{2}\right)}<0,
$$

which proves part (i). For part (ii), we compare (A.27) with (A.28) and conclude that

$$
\frac{\partial S_{2}^{2}}{\partial S_{1}}>\frac{\partial S_{2}^{1}}{\partial S_{1}}
$$

Using this result together with Theorem 1 ensures the unique solution given in Theorem 2 .

\section{References}

Anupindi, R., Y. Bassok, E. Zemel. 2001. A general framework for the study of decentralized distribution systems. J. Manufacturing Service Oper. Management 3 349-368.

Avsar, Z. M., M. Baykal-Gursoy. 2002. Inventory control under substitutable demand: A stochastic game application. Naval Res. Logist. 49 359-375.

Billingsley, P. 1986. Probability and Measure, 2nd ed. Wiley Interscience, New York.

Cachon, G. P. 2001. Stock wars: Inventory competition in a twoechelon supply chain with multiple retailers. Oper. Res. 49 658-674.

Cachon, G. P., P. Zipkin. 1999. Competitive and cooperative inventory policies in a two-stage supply chain. Management Sci. 45 936-953.

Chen, F. 1999. Decentralized supply chains subject to information delays. Management Sci. 45 1076-1090.

Cherikh, M. 2000. On the effect of centralisation on expected profits in a multi-location newsboy problem. J. Oper. Res. Soc. 51 755-761.

Das, C. 1975. Supply and redistribution rules for two-location inventory systems: One-period analysis. Management Sci. 21 765-776.
Eppen, G., L. Schrage. 1981. Centralized ordering policies in a multi-warehouse system with lead times and random demand. TIMS Stud. Management Sci. 16 51-67.

Fudenberg, D., J. Tirole. 1991. Game Theory. MIT Press, Cambridge, MA.

Gross, D. 1963. Centralized inventory control in multi-location supply systems. H. Scarf, D. Gilford, M. Shelly, eds. Multistage Inventory Models and Techniques. Stanford University Press, Stanford, CA, 47-84.

Krishnan, K. S., V. R. K. Rao. 1965. Inventory control in $N$ warehouses. J. Indust. Engrg. 16 212-215.

Lee, H., S. J. Whang. 1999. Decentralized multi-echelon supply chains: Incentives and information. Management Sci. 45 633-640.

Lippman, S. A., K. F. McCardle. 1997. The competitive newsboy. Oper. Res. 45 54-65.

Mahajan, S., G. van Ryzin. 2001. Inventory competition under dynamic consumer choice. Oper. Res. 49 646-657.

Parlar, M. 1988. Game theoretic analysis of the substitutable product inventory problem with random demand. Naval Res. Logist. 35 397-409.

Robinson, L. W. 1990. Optimal and approximate policies in multiperiod, multi-location inventory models with transshipments. Oper. Res. 38 278-295.

Rudi, N., S. Kapur, D. F. Pyke. 2001. A two-location inventory model with trasshipment and local decision making. Management Sci. 47 1668-1680.

Tagaras, G. 1989. Effects of pooling on the optimization and service levels of two-location inventory systems. IIE Trans. 21 250-257.

Tagaras, G. 1999. Pooling in multi-location periodic inventory distribution systems. Omega 27 39-59.

Wang, Q., M. Parlar. 1994. A three-person game theory model arising in stochastic inventory control theory. Eur. J. Oper. Res. 76 83-97. 